\title{
Transthyretin provides trophic support via megalin by promoting neurite outgrowth and neuroprotection in cerebral ischemia
}

\author{
JR Gomes ${ }^{1,2}$, RS Nogueira ${ }^{1,2}$, M Vieira ${ }^{1,2}$, SD Santos ${ }^{1,3}$, JP Ferraz-Nogueira ${ }^{1,3}$, JB Relvas ${ }^{1,3}$ and MJ Saraiva ${ }^{\star, 1,2,4}$
}

Transthyretin (TTR) is a protein whose function has been associated to binding and distribution of thyroid hormones in the body and brain. However, little is known regarding the downstream signaling pathways triggered by wild-type TTR in the CNS either in neuroprotection of cerebral ischemia or in physiological conditions. In this study, we investigated how TTR affects hippocampal neurons in physiologic/pathologic conditions. Recombinant TTR significantly boosted neurite outgrowth in mice hippocampal neurons, both in number and length, independently of its ligands. This TTR neuritogenic activity is mediated by the megalin receptor and is lost in megalin-deficient neurons. We also found that TTR activates the mitogen-activated protein kinase (MAPK) pathways (ERK1/2) and Akt through Src, leading to the phosphorylation of transcription factor CREB. In addition, TTR promoted a transient rise in intracellular calcium through NMDA receptors, in a Src/megalin-dependent manner. Moreover, under excitotoxic conditions, TTR stimulation rescued cell death and neurite loss in TTR KO hippocampal neurons, which are more sensitive to excitotoxic degeneration than WT neurons, in a megalin-dependent manner. CREB was also activated by TTR under excitotoxic conditions, contributing to changes in the balance between Bcl2 protein family members, toward anti-apoptotic proteins (Bc/2/ $\mathrm{BcIXL}$ versus Bax). Finally, we clarify that TTR KO mice subjected to pMCAO have larger infarcts than WT mice, because of TTR and megalin neuronal downregulation. Our results indicate that TTR might be regarded as a neurotrophic factor, because it stimulates neurite outgrowth under physiological conditions, and promotes neuroprotection in ischemic conditions.

Cell Death and Differentiation (2016) 23, 1749-1764; doi:10.1038/cdd.2016.64; published online 12 August 2016

TTR is synthesized in the liver (blood source) and choroid plexus (CSF-cerebrospinal fluid source). The physiological functions of TTR are the transport of thyroxine and retinol, through RBP (retinol-binding protein). More recently, TTR was described to have roles independent of its ligands, from neuroprotection in Alzheimer and schizophrenia, to the involvement in memory and learning. ${ }^{1}$ It was also associated with nerve regeneration in the peripheral nervous system (PNS). ${ }^{2}$ We have previously shown that TTR has a neuroprotective effect in focal cerebral ischemia in the central nervous system (CNS). ${ }^{3}$ Several other studies pointed in the same direction: (i) TTR can be a good predictor for young patients with stroke, because patients have worse clinical prognosis if they exhibit decreased serum TTR; ${ }^{4}$ (ii) smaller incidence of stroke in women, owing to neuroprotective action of sex steroids, which upregulate TTR in $\mathrm{CSF}^{5}{ }^{5}$ (iii) in a $C$. elegans model, a TTR-like protein was determinant in the recognition of apoptotic cells by phagocytes. ${ }^{6}$

TTR binds megalin (LRP-2), ${ }^{7,8}$ RAGE $^{9}$ (receptor for advanced glycation end products) and IGF-IR (insulin-like growth factor 1 receptor). ${ }^{10}$ Megalin has been mainly studied in kidney, but its function in the CNS is poorly understood. ${ }^{11}$ It binds metallothionein, clusterin and apolipoprotein-E, which have neuroprotective roles. ${ }^{12}$ Megalin activates intracellular pathways, such as Erk1/2 and Akt, leading to the activation of transcription factor CREB. ${ }^{13}$

Ischemic brain injury is a leading cause of mortality in Western countries. ${ }^{14}$ Tissue plasminogen activator is the only approved therapy for acute non-hemorrhagic stroke. However, this therapeutic strategy can only be used in the first $4.5 \mathrm{~h}$ after symptoms onset, making it available for only $4-7 \%$ of these patients. ${ }^{15}$ Excitotoxicity mediated by overactivation of glutamate receptors is one the major events in cerebral ischemia, playing a key role in neuronal death. Despite failure of previous generation of drugs, the new generation of excitotoxicity inhibitors may succeed, for example, Tat-NR2B9c peptide, is neuroprotective in both animals and patients. ${ }^{16,17}$ Excitotoxic mechanisms are characteristic of several other disorders. ${ }^{18}$

In the present study, we unraveled the molecular pathways involving TTR in CNS neurons both during physiologic and pathologic/ischemic conditions. We found that TTR promotes a robust neurite outgrowth response in neurons, through upregulation of intracellular calcium and MAPK pathways, triggered by its interaction with megalin. Moreover, TTR/ megalin interaction was found to be determinant for neuronal survival and neurite preservation, both in excitotoxic

\footnotetext{
${ }^{1}$ Instituto de Investigação e Inovação em Saúde (I3S), University of Porto, Porto, Portugal; ${ }^{2}$ Molecular Neurobiology Unit, IBMC- Institute for Molecular and Cell Biology, University of Porto, Porto, Portugal; ${ }^{3}$ Glial Cell Biology Unit, IBMC- Institute for Molecular and Cell Biology, University of Porto, Porto, Portugal and ${ }^{4}$ ICBAS-Instituto de Ciências Biomédicas Abel Salazar, Universidade do Porto, Rua de Jorge Viterbo Ferreira n² 228, 4050-313 Porto, Portugal

${ }^{*}$ Corresponding author: MJ Saraiva, Molecular Neurobiology, IBMC- Institute for Molecular and Cell Biology, University of Porto, Rua Alfredo Allen, 208, 4200-135 Porto, Portugal. Tel: +351 220408800; Fax: +351 225570770; E-mail: mjsaraiv@ ibmc.up.pt

Abbreviations: TTR, transthyretin; pMCAO, permanent middle cerebral artery occlusion; CREB, cAMP response element-binding protein; Bcl2, B-cell lymphoma 2; NMDA, N-methyl-D-aspartate; NR2A, N-methyl-D-aspartate 2A receptor

Received 17.3.16; revised 03.6.16; accepted 08.6.16; Edited by L Greene; published online 12.8.2016
} 
conditions in neuronal cultures, and in a mouse model of permanent middle cerebral artery occlusion (pMCAO).

\section{Results}

TTR promotes neurite outgrowth in WT and TTR KO cultured hippocampal neurons through megalin. TTR was shown to promote neurite outgrowth in the PNS, mainly in dorsal root ganglia neurons, ${ }^{2}$ but the molecular signaling pathways involved are yet to be explored, as well as whether TTR has a similar role in the CNS. To determine whether TTR has neuritogenic activity in the CNS, cultured hippocampal neurons from TTR KO mice were stimulated with recombinant mouse or human TTR (to address its potential use as a neuroprotective target in humans) using two concentrations, 55 and $300 \mu \mathrm{g} / \mathrm{ml}$, that mimic the two pools of TTR in the body, CSF and sera, respectively. ${ }^{19}$ These conditions induced $a$ rise in both neurite number (Figures $1 a$ and $b$ closed arrow) and neurite length, assessed by $\mathrm{MAP}_{2}$ immunocytochemistry (Figures $1 \mathrm{a}$ and $\mathrm{b}$ open arrow). The effect is dose-dependent and identical for human and mouse TTR. We observed the same neuritogenic activity of TTR in WT hippocampal neurons incubated with human TTR $300 \mu \mathrm{g} /$ $\mathrm{ml}$ (neurite number and length (Figure 1c)). To further confirm TTR as the protein responsible for these effects, we used an anti-TTR antibody, which blocked neurite outgrowth (Figure 1e). Moreover, when TTR KO neurons were stimulated with recombinant TTR variant (I84S), which has very low affinity for thyroxine and RBP ligands, ${ }^{20,21}$ they had a similar increase in neurite number and outgrowth (Figure 1d) to WT TTR, proving that TTR neurogenic activity is not related to its ligands. In the PNS, TTR neuritogenic activity was shown to be megalin-mediated. ${ }^{2}$ To investigate whether this occurred in CNS neurons, we used RAP (receptor associated protein), an LRP antagonist, ${ }^{22}$ which blocks megalin-TTR interaction. ${ }^{7}$ RAP blocked TTR-induced increase in neurite number and total length (Figure 1f). However, because RAP is a broad LRP inhibitor, we prepared hippocampal neuronal cultures from megalin $(+/-)$ TTR KO mice embryos, which have significant lower amounts of megalin than TTR KO cultures (Figure 1j). None of the TTR concentrations used promoted neurite outgrowth in these cultures (Figures $1 \mathrm{~g}$ and $\mathrm{h}$ ) in opposition with cultures from the littermates megalin $(+/+)$ TTR KO (Figure 1i), indicating that TTR neuritogenic activity in the CNS is megalin-mediated. Both TTR concentrations are over the $\mathrm{Kd}$ determined for the megalin-TTR interaction $(500 \mathrm{nM}){ }^{8}$ Moreover, expression of $\mathrm{LRP}_{1}$, a megalin-related protein, was not altered in these megalin (+/ - ) TTR KO neuronal cultures (Figure 11). We analyzed megalin expression in TTR KO cultured hippocampal neurons and observed that megalin is expressed in cell body and dendrites (not stained for tau), and to a lower extent in axons (colocalized with tau) (Figure 1m).

\section{Signaling pathways activated by TTR are megalin- dependent in cultured hippocampal neurons. We} addressed the downstream signaling pathways triggered by WT TTR in the CNS at different levels: (i) phosphorylation of ERK and Akt (Ser473); ${ }^{23}$ (ii) intracellular calcium homeostasis; ${ }^{23}$ (iii) Src family kinase activation (Tyr416); ${ }^{24}$ (iv) gene transcription activation assessed by CREB phosphorylation (Ser133). ${ }^{25}$ Stimulation of TTR KO cultured hippocampal neurons with recombinant mouse TTR $(55 \mu \mathrm{g} / \mathrm{ml})$, resulted in a significant rise of the phosphorylated levels of ERK (35\%) and Akt (23\%), 30 min after the stimulus (Figures $2 \mathrm{a}$ and $\mathrm{c}$, respectively). ERK phosphorylation levels were higher in shorter time points (data not shown). TTR evoked a sustained (30-50\%) activation of Src $30 \mathrm{~min}$ after stimulation (Figure $2 \mathrm{~b}$ ) and promoted a significant rise (20\%) of CREB phosphorylation/activation (Figure 2d). As intracellular calcium was shown to induce neurite outgrowth, ${ }^{26}$ we performed FRET assays using a ultrasensitive calcium indicator-yellow Cameleon-Nano (YC-Nano15). ${ }^{27}$ TTR KO hippocampal neurons stimulated with mouse TTR showed a significant and transient rise in intracellular calcium concentration, in a dose-dependent manner (Figure 2f), compared with PBS (Supplementary Figure S1). This effect (calcium from extracellular source; Supplementary Figure S1) is observed mainly in neuronal cell body (where the results were obtained), was also seen in neurites (quantitative data not shown), demonstrated in the representative image of FRET assay (Figure 2e). To understand whether megalin

Figure 1 TTR promotes neurite outgrowth in WTand TTR KO cultured hippocampal neurons through megalin, independent of interaction with its ligands. (a) TTR KO cultured hippocampal neurons were stimulated with recombinant mouse and human TTR ( 55 and $300 \mu \mathrm{g} / \mathrm{ml}$ ), immediately after plating for $24 \mathrm{~h}$, and stained with a MAP ${ }_{2}$ antibody. Neurite number and neurite sum length were quantified with ImageJ software. The results are the average \pm S.E.M. of 3-10 independent experiments. (b) Representative MAP ${ }_{2}$ staining of TTR KO cultured hippocampal neurons stimulated with TTR. (c) WT cultured hippocampal neurons were also stimulated with recombinant human TTR (300 $\mu \mathrm{g} / \mathrm{ml})$, immediately after plating, for $24 \mathrm{~h}$. Neurite number and neurite sum length were quantified as described in (a and $\mathbf{b})$. The results are the average \pm S.E.M. of five independent experiments. (d) Corresponds to the same stimulation of TTR KO hippocampal neurons with a recombinant mutant TTR (TTR I84S $55 \mu \mathrm{g} / \mathrm{ml}$ )). The results are the average \pm S.E.M. of three to four independent experiments. In (e), the results (neurite sum length) in similar experiments using TTR KO cultured hippocampal neurons treated with mouse TTR with or without an antibody against TTR are shown. The results are the average \pm S.E.M. of three to seven independent experiments. (f) TTR KO cultured hippocampal neurons were stimulated with recombinant mouse TTR $(300 \mu \mathrm{g} / \mathrm{ml})$ with or without RAP and stained with $\mathrm{MAP}_{2}$ to quantify neurite number and neurite sum length. The results are the average \pm S.E.M. of four to seven independent experiments. Megalin heterozygous TTR KO cultured hippocampal neurons were also stimulated with recombinant mouse TTR (55 and $300 \mu \mathrm{g} / \mathrm{ml})$ immediately after plating for $24 \mathrm{~h}$. Neurite number and neurite sum length for megalin $(+/-)$ TTR KO (h) and megalin $(+/+)$ TTR KO littermates (i) were quantified as described in ( $\mathbf{a}$ and $\mathbf{b}$ ). The results are the average \pm S.E.M. of three to four independent experiments. $(\mathbf{g})$ Representative MAP $\mathrm{M}_{2}$ staining of megalin $(+/-)$ TTR KO cultured hippocampal neurons stimulated with TTR. Megalin (j) and LRP1 (I) protein levels in TTR KO versus megalin heterozygous TTR KO hippocampal cultures were determined by western blot ( $n=10$ and 5 , respectively). ( $m$ ) Representative megalin, tau, MAP 2 and Hoechst 33342 staining of TTR KO cultured hippocampal neurons (7 DIV) of three independent experiments. Statistical analysis was performed using one-way ANOVA followed by Bonferroni's multiple comparison test performed for each condition or Student's unpaired $t$-test for two-groups only comparisons. ${ }^{\star \star \star} P<0.001,{ }^{\star \star} P<0.01,{ }^{\star} P<0.05$, n.s., not significant as compared with the control or as indicated. Scale bar in (b and $\mathbf{g}$ ) correspond to $20 \mu \mathrm{m}$ and in (m) to $10 \mu \mathrm{m}$ 
mediates signaling cascades activated by TTR, we incubated TTR KO neurons with RAP, and observed that it blocked the phosphorylation of ERK (Figure 2g), Akt (Figure 2h) and CREB (Figure 2i). In the same manner, we stimulated megalin +/ - TTR KO hippocampal neurons with TTR (55 $\mu \mathrm{g} /$ $\mathrm{ml}$ ), and observed that TTR stimulation was unable to activate ERK (Figure 2j), Src (Figure 2l), Akt (Figure 2m) and CREB (Figure 2n). The same happened with intracellular
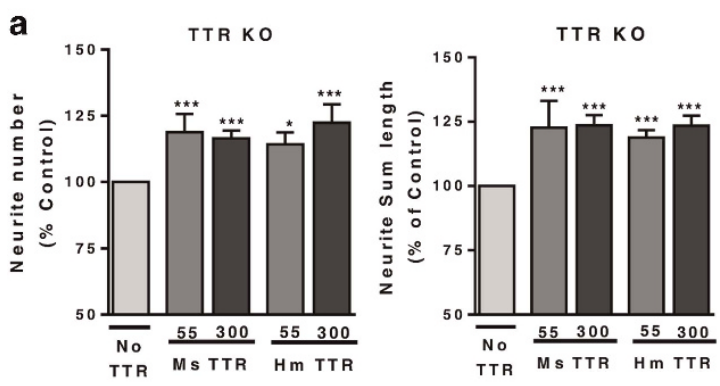

b
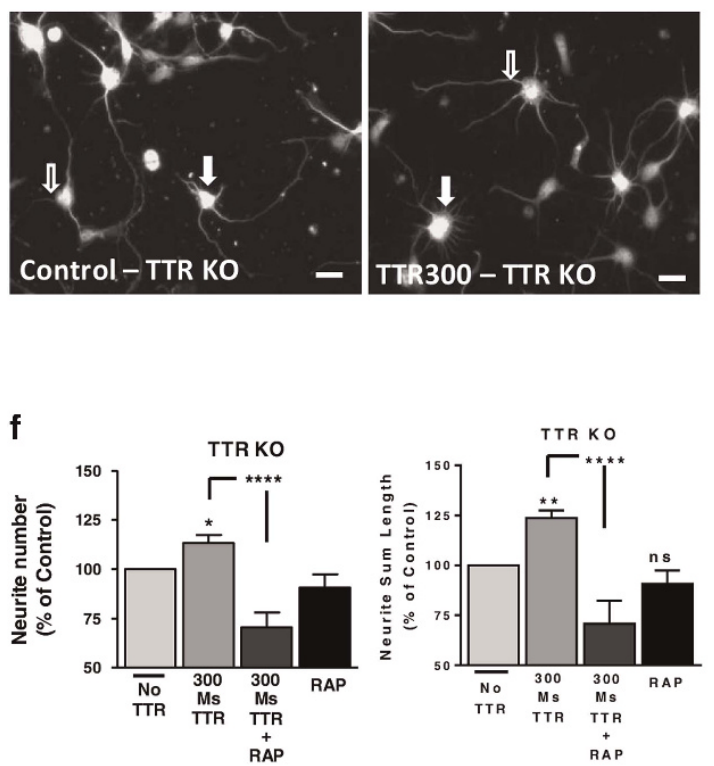

g
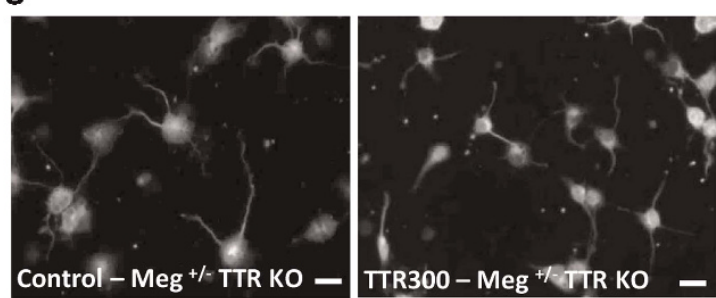

m
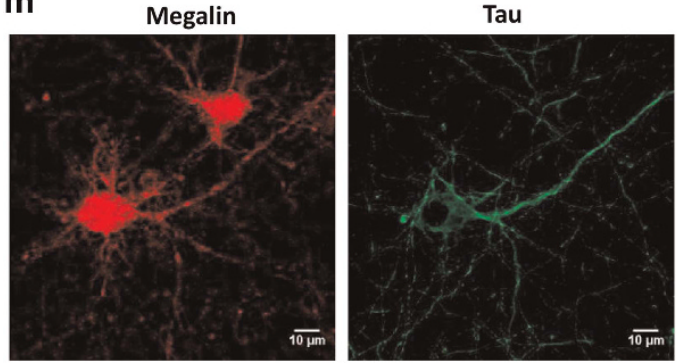

C
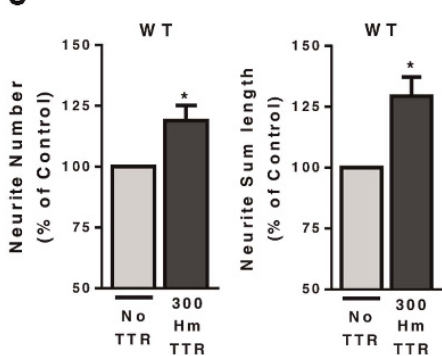

j

e
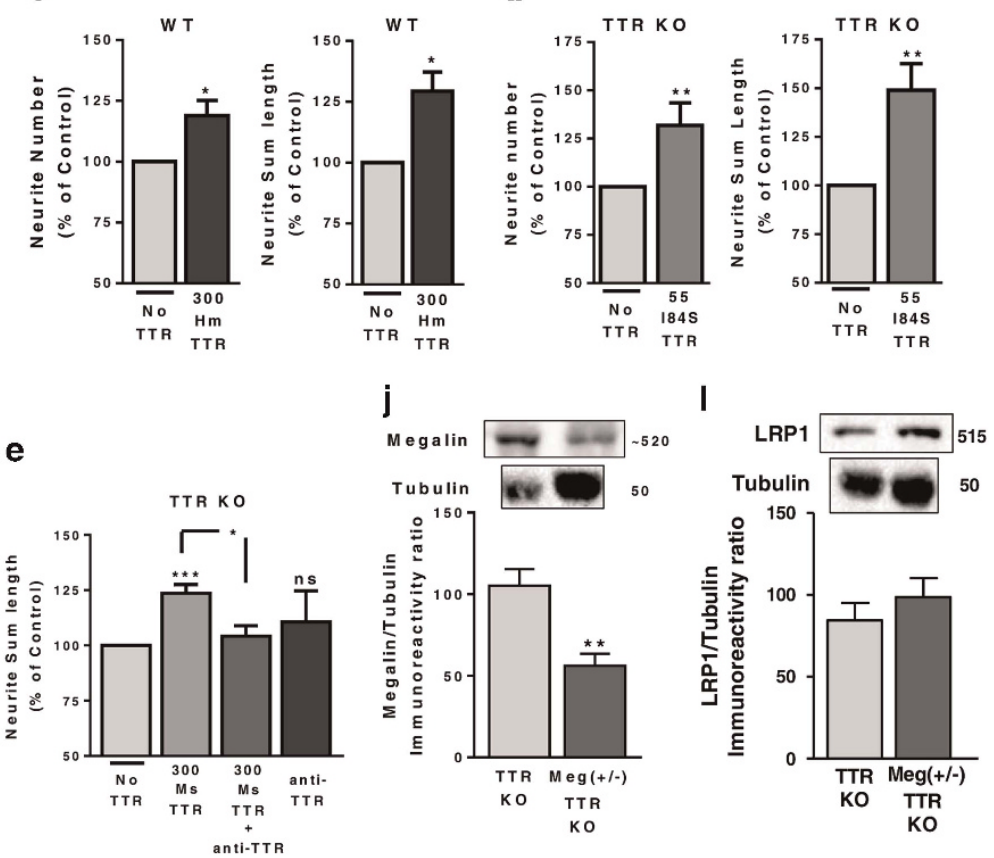

h
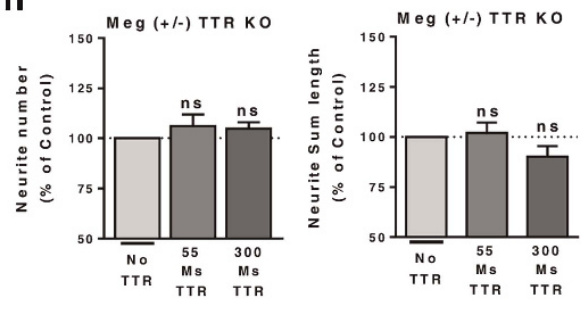

i
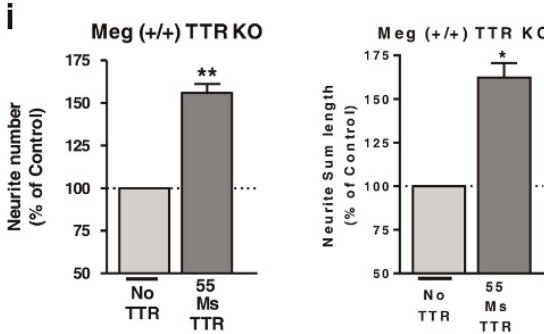

Hoechst
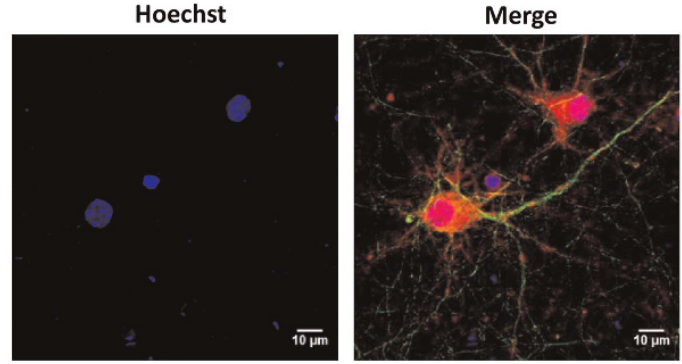
calcium, as detected by FRET (Figure 20), in opposition to the megalin +/+ TTR KO littermate neurons (Figure 2p). Thus, these signaling pathways activated by TTR through megalin seem to be responsible for TTR neurite outgrowth.

TTR transiently activates NMDA receptors through a megalin/Src mechanism. As megalin has a Src homology domain (SH3), ${ }^{12}$ and Src constitutes a crucial point of convergence for signaling pathways, we reasoned that Src could be the bridging molecule between megalin and downstream signaling pathways. We performed FRET assay with the calcium probe in TTR KO neurons incubated with TTR in the presence of SKI, a Src inhibitor, and concluded that SKI blocked intracellular calcium rise induced by TTR (Figure 3a). Then, we hypothesized that NMDA could be responsible for this increase in calcium, because Src regulates NMDA receptor activity. ${ }^{28}$ Both kynurenic acid (Figure $3 b$ ), a broader AMPA/NMDA inhibitor, and MK801 (Figure 3c), a specific NMDA inhibitor, blocked the increase in intracellular calcium promoted by TTR. In addition, $10 \mu \mathrm{M}$ NMDA stimuli promoted a similar increase in intracellular calcium as mouse TTR (300 $\mu \mathrm{g} / \mathrm{ml})$ stimulus (Figure $3 \mathrm{~d}$ ). To understand whether Src a

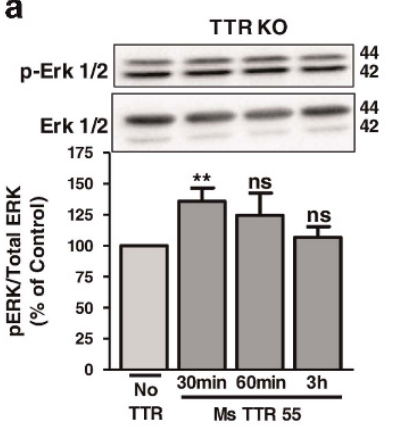

b

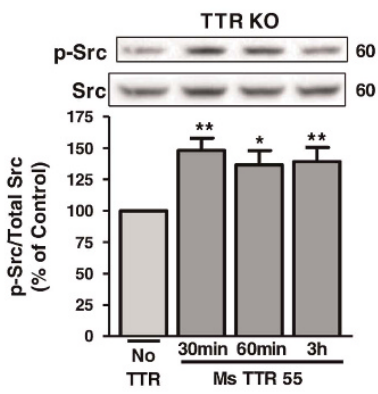

C

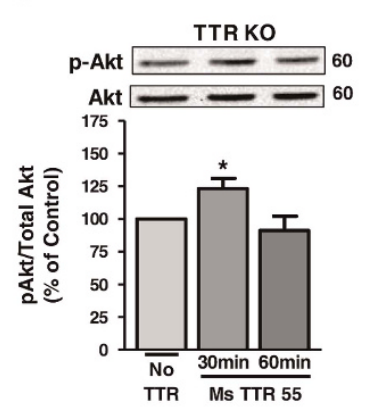

d

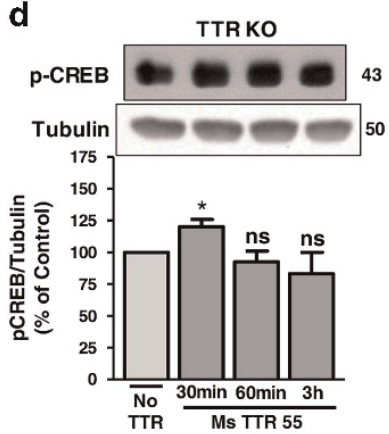

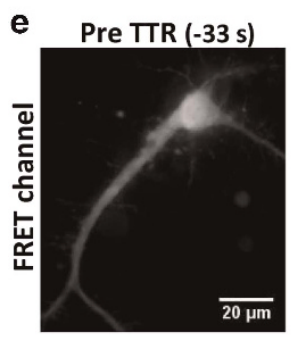
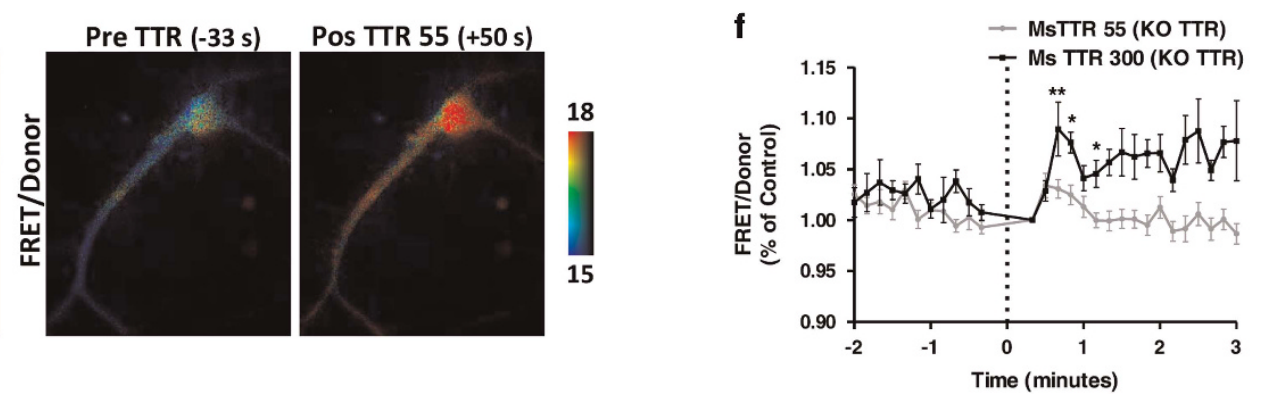

g

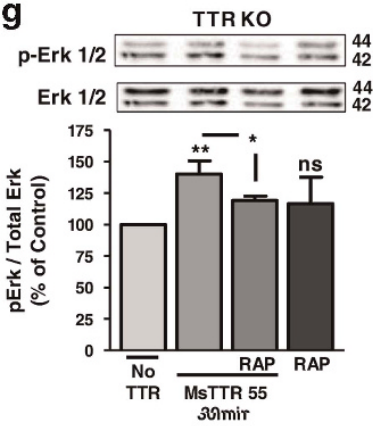

h

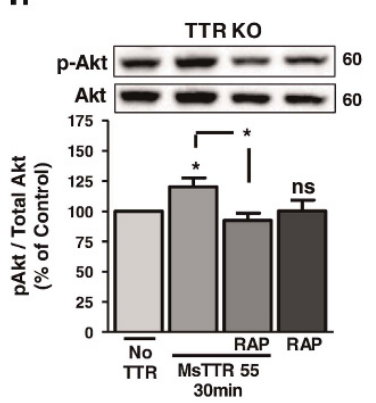

i

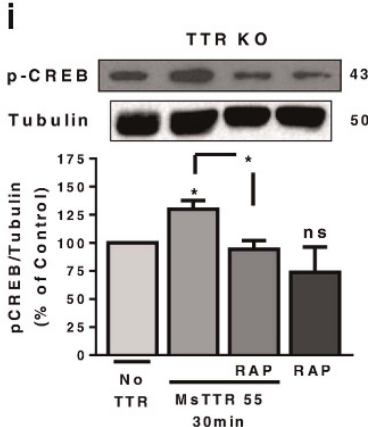

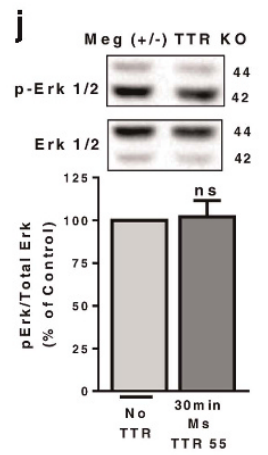

I
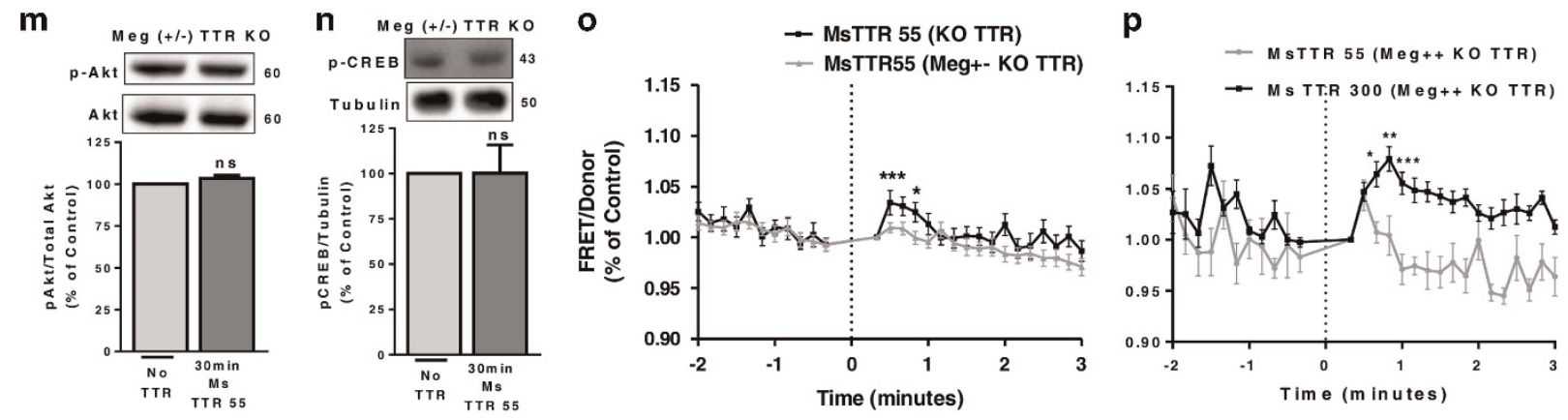
was also governing TTR signaling pathways, we stimulated TTR KO cultured neurons with mouse TTR $(55 \mu \mathrm{g} / \mathrm{ml})$ and $\mathrm{SKI}$, and observed that it blocked the activation of ERK (Figure 3e), Akt (Figure 3f) and CREB (Figure 3g). Altogether, we concluded that Src is the key regulator of the signaling pathways triggered by TTR/megalin.

TTR KO hippocampal neurons are more sensitive to an excitotoxic insult than WT counterparts. To address TTR neuroprotection, we subjected TTR KO and WT cultured hippocampal neurons to excitotoxic conditions, by a transient incubation with high glutamate concentration $(125 \mu \mathrm{M}$, for $20 \mathrm{~min}$ ), and further incubating the neurons in cultureconditioned medium for $14 \mathrm{~h}$. These conditions induce $40-50 \%$ apoptotic cell death, ${ }^{29}$ resembling neuronal death in penumbra of a stroke. ${ }^{30}$ TTR KO neurons are more sensitive to this excitotoxic insult than WT neurons, showing less viable dendrites in $\mathrm{MAP}_{2}$ immunocytochemistry assays (Figure 4a) and western blot data (Figure 4b). Axons, observed with Tau staining, are affected to the same extent as dendrites, with TTR KO neuronal cultures showing higher axonal degeneration than WT neuronal cultures (Figures 4c and d). The same was shown in green fluorescent protein (GFP)-transfected WT and TTR KO hippocampal neurons subjected to an excitotoxic insult $48 \mathrm{~h}$ after transfection, with transfected TTR KO neurons showing a much lower number of GFP-stained neurites than transfected WT neurons (Figure 4e). To assess the effect of TTR in cell death, we analyzed nuclear morphology by Hoechst 33342, $14 \mathrm{~h}$ after the excitotoxic insult. TTR KO neuronal cultures showed significantly more dead neurons than WT counterparts (Figures $4 \mathrm{f}$ and $\mathrm{g}$ ). TTR could prevent neurite degeneration induced by glutamate stimulation, when added $(300 \mu \mathrm{g} / \mathrm{ml})$ after the excitotoxic insult, observed by $\mathrm{MAP}_{2}$ immunostaining (Figure $4 \mathrm{~h}$ ), neurite quantification (Figure 4i) and $\mathrm{MAP}_{2}$ western blot (Figure 4j). Tau protein levels were not rescued (Figure 4j), indicating that TTR is mostly neuroprotective at dendrite level.

TTR promotes neuronal survival, through megalin. To investigate the interplay between TTR and megalin in CNS neuroprotection, we subjected megalin $(+/-)$ TTR KO hippocampal neurons to an excitotoxic insult, and added
TTR after the insult. We observed that TTR did not prevent dendrite degeneration induced by glutamate, both in dendrite number and total length (Figures $5 \mathrm{a}$ and $\mathrm{b}$ ). To understand whether TTR also rescues neuronal survival with/without megalin, we pre-incubated TTR KO neurons with TTR $(300 \mu \mathrm{g} / \mathrm{ml}), 6 \mathrm{~h}$ before excitotoxic stimulus, and observed a reduced cell death (Figures $5 \mathrm{c}$ and $\mathrm{d}$ ). When added after glutamate, TTR was unable to protect neurons (Figure $5 \mathrm{e}$ ). To understand whether megalin was involved in TTR neuroprotection at neuronal survival level, we performed the same experimental design using megalin $(+/-)$ TTR KO neurons. We realized that neither TTR pre- or post-incubation, 300 or $55 \mu \mathrm{g} / \mathrm{ml}$ (data not shown), could protect to any extent cell survival (Figures $5 f$ and $g$ ). Megalin $(+/+)$ TTR KO littermates show the same level of neuroprotection observed in TTR KO cultures (data not shown). We found that TTR was capable of activating phospho-CREB (Figure $5 \mathrm{i}$ ), and probably Akt, with a tendency shown (Figure $5 \mathrm{~h}$ ), in excitotoxic conditions. As megalin was shown to be necessary for the neuroprotective action of TTR, we quantified megalin mRNA levels, after glutamate stimulation ( $4 \mathrm{~h}$ ), in both TTR KO and WT cultures. Megalin mRNA was significantly upregulated in WT cultures (Figure 5j), in opposition to TTR KO cultures (Figure 5i). In WT neurons, there is the possibility of endogenous TTR being produced (although not consensual). ${ }^{31}$ We did not detect TTR protein by western blot neither in cell extracts nor in culture-conditioned medium (data not shown). However, we found that TTR mRNA is highly upregulated in these cultures after excitotoxic stimulus (4 h) (Figure $5 \mathrm{~m}$ ).

TTR neuroprotection involves the activation of antiapoptotic signaling pathways. As CREB was activated when TTR was added, after excitotoxic conditions (Figure 5i), we investigated whether phospho-CREB activates antiapoptotic genes, such as members of $\mathrm{Bcl} 2$ protein family. ${ }^{32}$ We stimulated TTR KO neurons with TTR (human, $55 \mu \mathrm{g} / \mathrm{ml}$ ) and observed that Bcl2 (Figure 6a) and BclXL mRNA levels (Figure 6c) were highly upregulated. Bcl2 protein levels were also upregulated 60 min upon TTR stimulation (Figure 6b). Bax was not altered at the mRNA level (Figure 6d) or protein level (Figure 6e). In WT neurons, a similar pattern was seen, that is, upregulation of $\mathrm{Bcl} 2$ (Figure $6 \mathrm{f}$ ) and $\mathrm{BclXL}$ mRNA

Figure 2 Signaling pathways activated by TTR are megalin-dependent. TTR signaling activity was assessed by analyzing the phosphorylation levels of ERK (a, $n=3-14$ ), SRC (Tyr416) (b, $n=6-9)$, Akt (Ser473) (c, $n=3-9)$ and CREB (Ser133) (d, $n=3-14$ ) following stimulation of TTR KO cultured hippocampal neurons (7 DIV) with recombinant mouse TTR $(55 \mu \mathrm{g} / \mathrm{ml})$ for different time points. The results are the average + S.E.M. of 3-14 independent experiments. (e) FRET image and pseudocolor ratio images (FRET/ Donor channels) of a representative TTR KO cultured hippocampal neuron expressing yellow Cameleon-Nano (YC-Nano15) stimulated with mouse TTR (55 $\mu \mathrm{g} / \mathrm{ml})$. Scale bar represents $20 \mu \mathrm{m}$ and the FRET/Donor images were coded according to the indicated pseudocolor scale. (f) Time course of normalized FRET/Donor values in cell body of YC-Nano15-transfected TTR KO cultured hippocampal neurons (7 DIV) stimulated with two concentrations of mouse TTR (55 and $300 \mu \mathrm{g} / \mathrm{ml}$ ), (two to three independent experiments, four to six neurons in each experiment). TTR administration was carried out at the ' $0 \mathrm{~s}$ ' (line with dashes in the graph), but first time analyzed after stimulation is ' $0.33 \mathrm{~s}$ '. To address the role of megalin in TTR signaling activity, we used RAP, an LRP inhibitor and analyzed the phosphorylation levels of ERK ( $\mathbf{g}, n=4-15)$, Akt (Ser473) ( $h$, $n=5-10)$ and CREB (Ser133) (I, $n=3-12)$ following stimulation of TTR KO cultured hippocampal neurons (7 DIV) with recombinant mouse TTR (55 $\mu \mathrm{g} / \mathrm{ml})$ in the presence or absence of RAP $(350 \mu \mathrm{g} / \mathrm{ml}, 30 \mathrm{~min}$ pre-incubation). The results are the average \pm S.E.M. of 3-15 independent experiments. TTR signaling activity was also addressed in megalin heterozygous TTR KO cultured hippocampal neurons (7 DIV) by analysis of the phosphorylation levels of ERK (j, $n=3), \operatorname{Src}(\operatorname{Tyr} 416)(\mathrm{I}, n=4)$, Akt (Ser473) ( $\mathbf{m}, n=3)$ and CREB (Ser133) (n, n=3) following stimulation with recombinant mouse TTR $(55 \mu \mathrm{g} / \mathrm{ml})$ for $30 \mathrm{~min}$. The results are the average \pm S.E.M. of three to four independent experiments. (o) Time course of normalized FRET/Donor values in cell body of YC-Nano15-transfected TTR KO and megalin (+/ - ) TTR KO cultured hippocampal neurons stimulated with mouse TTR (55 $\mu \mathrm{g} / \mathrm{ml})$ (three independent experiments, five neurons in each experiment). (p) Same experimental design as in (o), but megalin (+/+) TTR KO littermate cultures were used and challenged with two concentrations of mouse TTR (55 and $300 \mu \mathrm{g} / \mathrm{ml}$ ) (one independent experiment for each, five neurons in each experiment). Statistical analysis was performed using one-way ANOVA followed by Bonferroni's multiple comparison test performed for each condition or Student's unpaired $t$-test for two-groups only comparisons. ${ }^{* *} P<0.001,{ }^{* \star} P<0.01,{ }^{*} P<0.05$, n.s., not significant as compared with the control or as indicated 
a

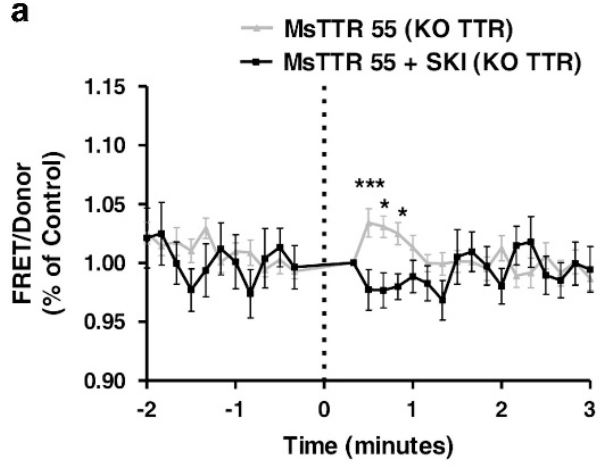

C
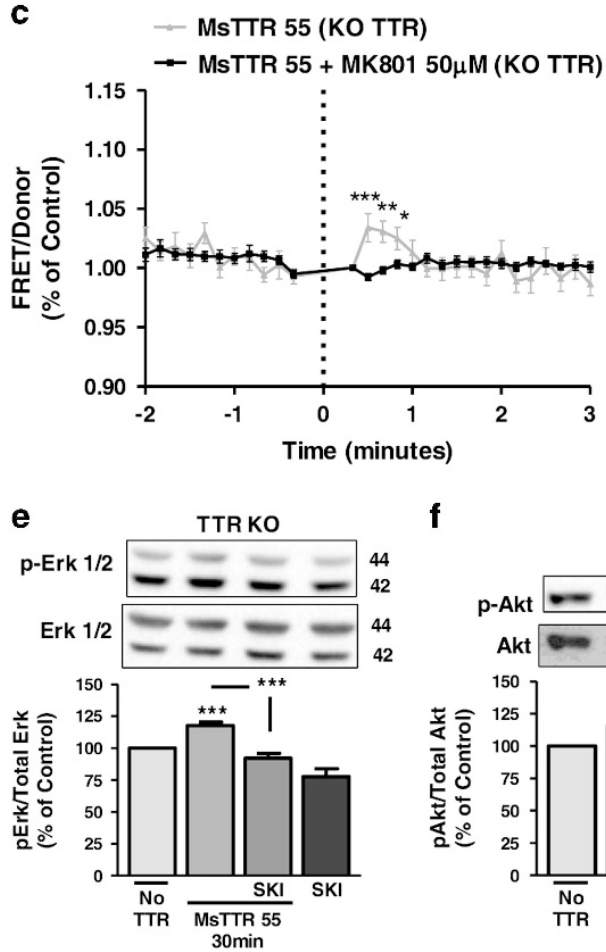

f

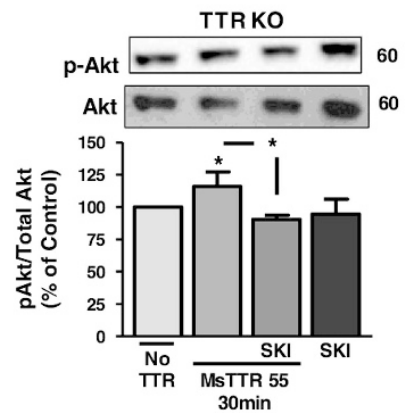

b

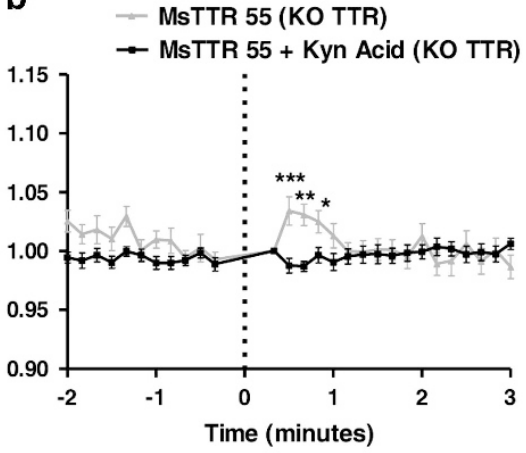

d

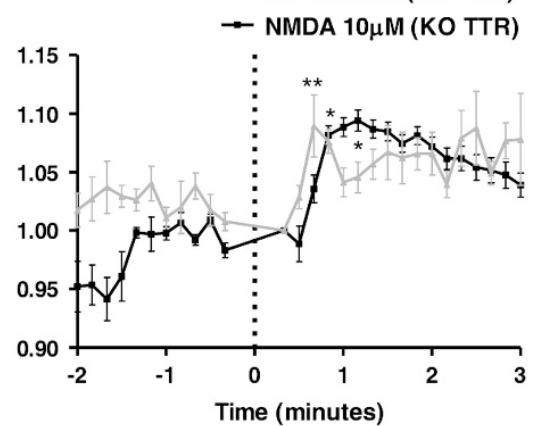

g

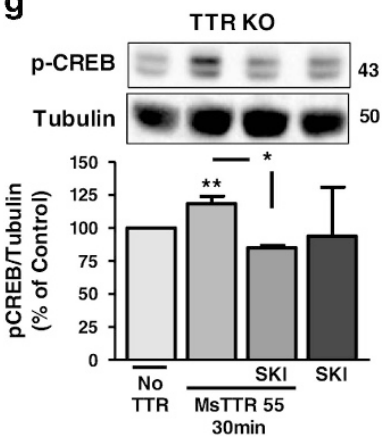

Figure 3 TTR transiently activates NMDA receptors through a megalin/Src mechanism. (a) Time course of normalized FRET/Donor values in cell body of YC-Nano15transfected TTR KO cultured hippocampal neurons (7 DIV) stimulated with mouse TTR (55 $\mu \mathrm{g} / \mathrm{ml})$ with or without Src inhibitor Ski (200 nM, $15 \mathrm{~min}$ pre-incubation) (for MsTTR, data are from Figure $2 f$ and for MsTTR+SKI, three independent experiments, five to six neurons in each experiment). TTR administration was carried out at the ' $0 \mathrm{~s}$ ' (line with dashes in the graph), but first time analyzed after stimulation is ' 0.33 s'. (b, $\mathbf{c}$ and d) Same experimental design as in (a) but using the NMDA/AMPA receptor inhibitor kynurenic acid (b, 2 mM, 15 min pre-incubation) (for MsTTR, data are from Figure 2f and for MsTTR+Kyn acid, three independent experiments, six neurons in each experiment), or the NMDA inhibitor MK801 (c, $50 \mu \mathrm{M}, 15$ min pre-incubation) (for MsTTR, data are from Figure 2f and for MsTTR+MK801, three independent experiments, four to six neurons in each experiment) or stimulate neurons with mouse TTR $(300 \mu \mathrm{g} / \mathrm{ml})$ versus an NMDA $(10 \mu \mathrm{M})$ stimulus (d, for MsTTR, data are from Figure $2 f$ and for NMDA, one independent experiment, five neurons). To address the role of Src in TTR signaling activity, we used the Src inhibitor, SKI, and analyzed ERK (e, $n=3-17)$, Akt (Ser473) (f, $n=3-6)$ and CREB phosphorylation levels (Ser133) (g, $n=3-6$ ) following stimulation of TTR KO cultured hippocampal neurons (7 DIV) with recombinant mouse TTR (55 $\mu \mathrm{g} / \mathrm{ml})$ with or without SKI (200 nM, 15 min pre-incubation). The results are the average \pm S.E.M. of 3-17 independent experiments. Statistical analysis was performed using one-way ANOVA followed by Bonferroni's multiple comparison test performed for each condition as compared with the control or as indicated. ${ }^{* \star} P<0.001,{ }^{* *} P<0.01,{ }^{*} P<0.05$, n.s., not significant

levels (Figure 6g), and no change in Bax mRNA (Figure 6h). We expected the balance Bcl2/Bax levels governing cell death to be more relevant in excitotoxic conditions, for cell survival. ${ }^{33} \mathrm{Bcl} 2$ mRNA levels were downregulated after glutamate stimulation in both WT (Figure 6l) and TTR KO cultures (Figure 6i). TTR pre-incubation before excitotoxic stimulus resulted in rescue of $\mathrm{Bcl} 2$ downregulation, in both TTR KO (Figure 6i) and WT cultures (Figure 6I). Regarding Bax mRNA levels, they did not change significantly after glutamate stimulation in both WT (Figure $6 \mathrm{~m}$ ) and TTR KO cultures (Figure 6j). Yet, when TTR was pre-incubated before the excitotoxic stimulus, Bax levels were significantly downregulated in the WT neuronal cultures (Figure $6 \mathrm{~m}$ ), and with a clear tendency for downregulation in TTR KO cultures (Figure 6j). Taken together, the results clearly indicate that TTR shifts the balance of the Bcl2 protein family members toward anti-apoptotic proteins resulting in less neuronal death. 
TTR neuroprotection in vivo (pMCAO) is also megalindependent. Having identified megalin as the receptor involved in the transduction of TTR neuroprotection in hippocampal neuronal cell culture, we investigated whether megalin was involved and/or affected in a mice stroke modelpMCAO. Wild-type TTR and TTR KO mice (both $\mathrm{HSF}+\mathrm{I}_{-}$ background) were subjected to ischemia by $\mathrm{PMCAO}$ and analyzed $24 \mathrm{~h}$ later. Megalin and TTR (only in WT TTR mice, data not shown) immunoreactivity was increased, in the infarct area only, of both WT TTR and TTR KO mice (Figures $7 \mathrm{a}$ and $\mathrm{b}$ ). To clarify megalin upregulation in vivo, we quantified megalin $\mathrm{mRNA}$ and protein, in different brain areas of TTR KO and WT PMCAO mice. We found that WT mice upregulated megalin protein and mRNA in the infarct areas (IF Ipsi;P-IF Ipsi) versus corresponding non-infarct areas (IF-Contra;P-IF Contra) (Figures 7c and d). In opposition, megalin protein and mRNA in TTR KO mice are unchanged between the corresponding brain areas (Figures 7c and d). RAGE and IGF-IR (also bind TTR) did not show any changes between WT and TTR KO mice (data not shown). Through immunohistochemistry, we found that cells that were upregulating megalin in the infarct area of the pMCAO WT mice were neurons, as they fully co-localize with $\beta$ III-tubulin (Figure 7e). Moreover, we unraveled, through TUNEL staining, that most of megalin-positive cells in WT TTR mice were alive (80\%), whereas in KO TTR mice, only $50 \%$ survived (Figures $7 f$ and $g$ ). Santos et al. ${ }^{3}$ also demonstrated that TTR-positive cells were neurons, as we confirmed in this work, but did not clarify whether neurons were alive or dead. Via immunohistochemistry, we observed that all the TTR-positive cells co-localize with megalin (Figure 7h). In addition, by triple staining TTR, TUNEL and Hoechst 33342, we found that most of TTR-positive neurons in WT TTR mice were alive (90\%) (Figures 7i and j).

\section{Discussion}

In this study, we show that TTR has megalin-dependent neuritogenic activity on cultured hippocampal neurons, either from WT or TTR KO mice under physiologic conditions. More meaningful is the fact that TTR neuronal action is important in pathological/excitotoxic conditions. TTR is neuroprotective both for neuronal survival and neurite preservation under excitotoxic conditions, through the activation of well-known neuroprotective megalin-dependent signaling pathways and transcription factors. In addition, we demonstrate that TTR neuroprotective role in a focal cerebral ischemia model is also megalin-dependent.

The neuritogenic activity that we describe for TTR in CNS neurons (Figures $1 \mathrm{a}$ and $\mathrm{b}$ ) has been observed previously in the PNS (dorsal root ganglia neurons), ${ }^{2,34}$ indicating a widespread action over neuronal populations. Moreover, we describe that TTR function in promoting neurite outgrowth is independent of its ligands, a similar effect observed by Fleming et al. $^{34}$ in the PNS. Other studies described that TTR KO mice have spatial learning and memory deficits, in Morris water maze testing. ${ }^{35,36}$ TTR has also been associated with the maintenance of memory capacities during aging, because its hippocampal gene expression is downregulated in aged animals. ${ }^{37}$ So, this neuritogenic activity of TTR might be correlated with this role of TTR in memory and learning, as seen for other molecules. ${ }^{38}$ Although it can be due to other TTR pathways, a connection to be explored in the future. In agreement, TTR was found to be highly upregulated in the hippocampus of mice under an enriched environment housing compared with standard housing controls, ${ }^{39}$ indicating that it might be important to sustain enhanced memory function and recovery from lesion (enriched environment versus standard housing).

Megalin was shown to be important in the neuritogenic activity of other molecules such as metallothioneins ${ }^{40}$ and $a 2$ macroglobulin $(a 2-\mathrm{M}){ }^{25}$ We now demonstrate that TTR neuritogenic activity in cultured hippocampal neurons (CNS) is mediated by megalin, (Figures 2a-d), whereas LRP1 does not seem to be involved.

We found that TTR interaction with megalin activates the MAP kinase, ERK, Akt and Src, which ultimately lead to the upregulation of the CREB transcription factor (Figures 3a-d), as seen for other LRP ligands. TTR also contributes to a significant rise in intracellular calcium (Figure $3 \mathrm{~g}$ ) that might underlie the neurite outgrowth triggered by TTR. Similarly, a2-M was shown to promote neurite outgrowth in cortical neurons through ERK1/2, CREB and intracellular calcium changes, ${ }^{25}$ but in this case, LRP1 was involved. ${ }^{24}$ We show that the rise in intracellular calcium promoted by TTR occurs through NMDA receptors regulated by Src (Figure 5), allowing more calcium influx to neurons, probably through the phosphorylation of Nr2A/2B subunits, increasing channel gating and the probability of the channel to be in the open state. ${ }^{28} \mathrm{~A}$ similar activation of NMDA receptors by other LRP receptors was described by Qiu et al. ${ }^{41}$ for a2-M. Moreover, the Src kinase family has been described as a crucial point of convergence for signaling pathways that subsequently enhance NMDA receptor activity. ${ }^{28}$ This can also be a neuroprotective strategy, because it has been already demonstrated in a global ischemia model that NR2A receptor activates ERK1/2-CREB signaling pathways, that ultimately enhance BDNF and Bcl2 expression, decreasing hippocampal CA1 neuronal death. ${ }^{42}$

Importantly, we demonstrated that TTR KO neurons are more sensitive to excitotoxic insults than WT counterparts, both at neuronal survival and neurite degeneration levels, and that TTR could partially rescue dendrites if added after the insult (Figure 6). This neurite neuroprotection will allow a higher trophic support by the neurotrophic factors (such as BDNF, NGF and TTR) that are exchanged between neuronal processes, allowing the neuronal network to survive and be more resistant to deleterious stimuli. ${ }^{43,44}$ In a similar manner, TTR was shown to be important in nerve regeneration, as TTR $\mathrm{KO}$ mice have dorsal root ganglia neuron neurite outgrowth impairment and decreased regeneration after never injury. ${ }^{34}$ Moreover, local delivery of TTR to the crushed nerves rescues the regeneration phenotype of TTR KO mice. ${ }^{2}$ Regarding cell survival, TTR was only able to partially protect neurons when added before, but not after, the excitotoxic insult (Figures 7b and $c$ ), indicating that the neuroprotective role of TTR in cell survival probably requires de novo protein synthesis. Altogether, neuroprotection by TTR acts in excitotoxic conditions of neuronal cultures and in pMCAO model in a megalindependent manner, involving the signaling pathways described above. A recent work also points for megalin as a 
a

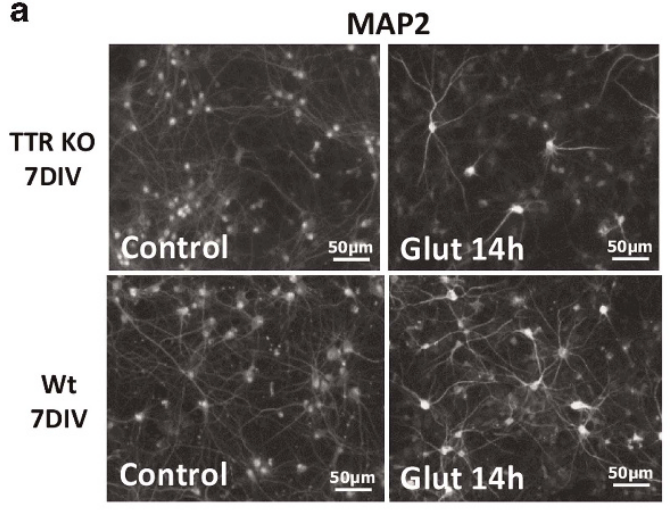

b
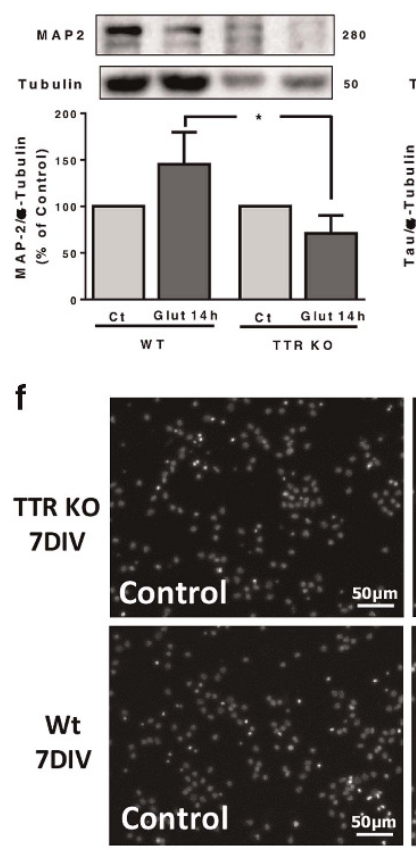

d
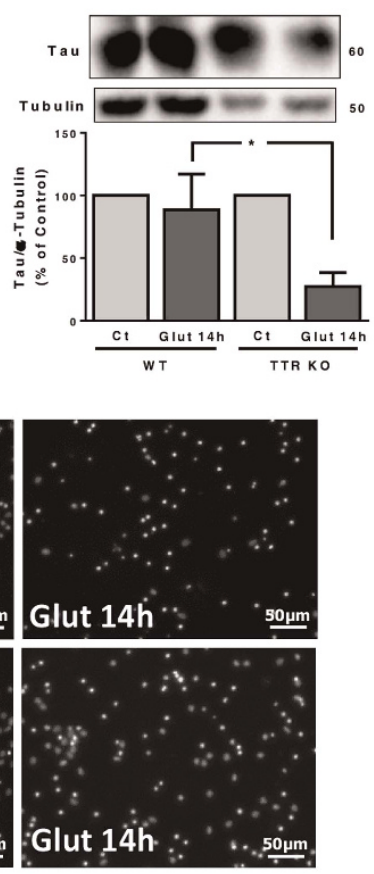

c
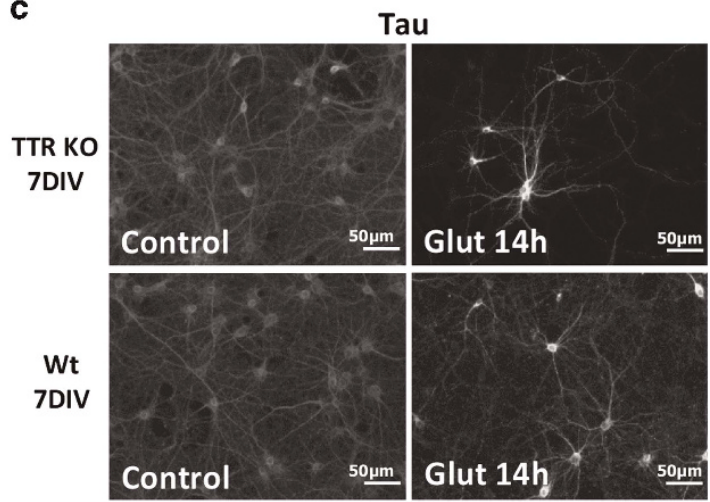

e

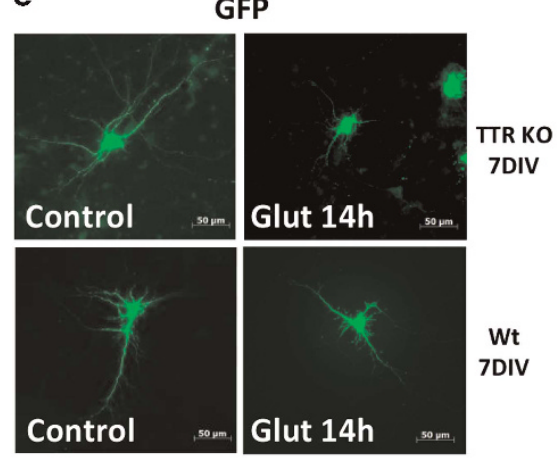

g

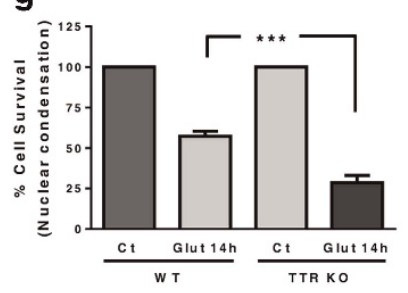

h

TTR KO
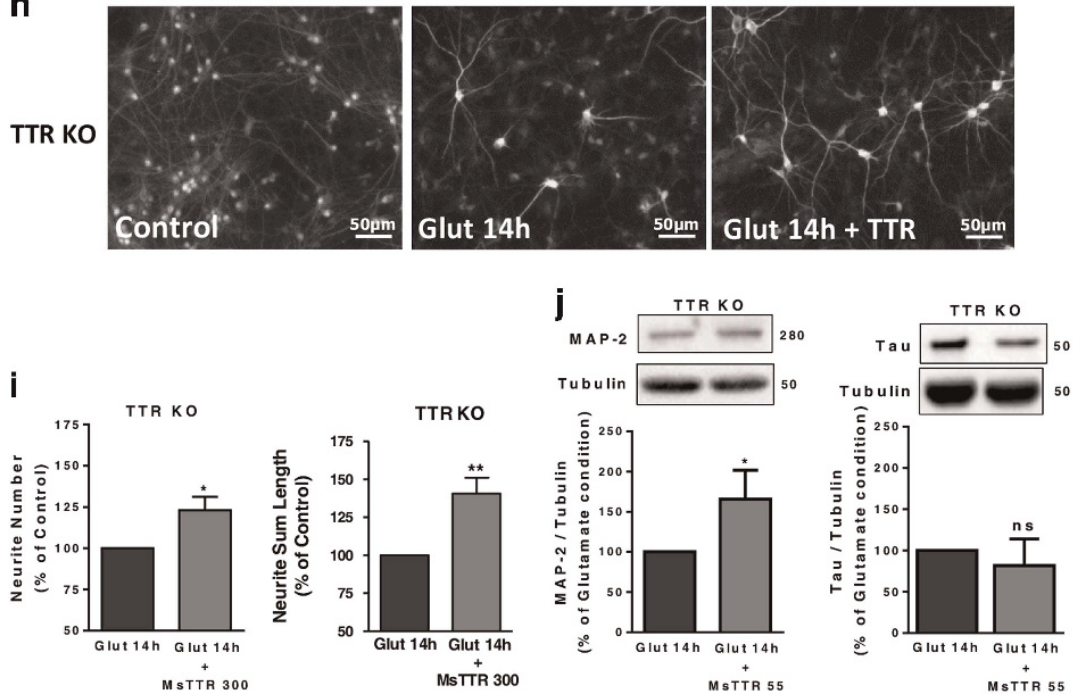
preponderant receptor for cell proliferation and survival, as expression of megalin was observed in the majority of malignant melanoma tumors $(60 \%)$ versus benign counterparts $(20 \%){ }^{45}$

TTR shifts the balance of Bcl2 proteins toward anti-apoptotic proteins resulting in reduced cell death. These results resemble those observed in a kidney cell line, where NGAL (neutrophil gelatinase-associated lipocain) was able to reduce apoptosis in a hypoxia-reperfusion model, by regulating Bax and Bcl2 levels, in a megalin-dependent manner. ${ }^{46}$ The control of $\mathrm{Bcl} 2$ proteins has also been suggested as a strategy to treat neurodegenerative disorders, such as Parkinson. ${ }^{33}$

In a murine model of Alzheimer disease, it was described that neurons transcribe TTR mRNA and secrete the protein in small amounts, contributing to a neuroprotective effect against $A \beta$ aggregates. ${ }^{31}$ We verified that TTR $\mathrm{mRNA}$ levels were also upregulated in ischemic challenged WT neuronal cultures (Figure $7 \mathrm{~m}$ ). TTR was also shown to be upregulated (in plasma) in ischemic preconditioning both in rats $^{47}$ and humans. ${ }^{48}$ In a transient focal cerebral ischemia model, TTR was upregulated in $\mathrm{CSF}^{49}$

We found in pMCAO mice that neurons that overexpress megalin in the infarct areas of WT mice survive significantly more than the neurons of TTR KO mice, confirming the role of megalin in neuroprotection induced by TTR in vivo (Figures $7 f$ and $\mathrm{g}$ ). Besides, we found that most of the neurons in the infarct area of WT mice also upregulate TTR and megalin (Figure 7h), and almost all are alive (Figures 7j and i), like we observed for WT neuronal cultures after an excitotoxic insult (Figure $4 \mathrm{f}, \mathrm{g}$ ). These results definitely indicate that megalin is responsible for the TTR-induced neuroprotection in cerebral ischemia. Hence, the upregulation of TTR in CSF and/or megalin neuronal upregulation should be addressed as potential preventive therapies for stroke.

Together, these findings indicate that TTR could be described as a new neurotrophic factor, which promotes neurite outgrowth in physiological conditions through upregulation of intracellular calcium and a Src/ErK/Akt/CREB pathway in a megalin-dependent manner, and is neuroprotective at different levels in pathological ischemic conditions also through megalin, either in vitro and in vivo as depicted in Supplementary Figure S2. These two interrelated proteins, megalin and TTR, could be further explored as possible endogenous neuroprotective targets, which can be potentiated in a novel preventive/prognostic strategy in different pathologies, certainly in stroke.

\section{Materials and Methods}

Animals. The number of mice handled for this research was approved by the Institutional and National General Veterinary Board Ethical Committees according to National and European Union rules. Three- to six-month-old TTR wild-type $(+/+)$, TTR KO $(-/-)^{50}$ and megalin $(+/-)$ TTR KO mice in a 129/svJ background were used for the hippocampal neuronal cultures. Three to six-month-old TTR KO $(-/-)$ and control littermates under a HSF1 $(+/-)$ background (129/svJ) were used for the pMCAO experiments. ${ }^{3}$ Megalin heterozygous mice were kindly provided by Dr. Thomas Willnow, Max-Delbrueck Center for Molecular Medicine, Berlin, Germany. ${ }^{51}$ The animals were maintained under a $12 \mathrm{~h}$ light/dark cycle in type II cages in specific pathogen-free conditions (microbiological heath status available). Animals were fed with regular rodents chow and tap water ad libitum. Genotypes were determined from tail-extracted genomic DNA, using primers for the detection of exon 2 of TTR (which is disrupted in TTR - / - by insertion of a neomycin resistance gene), megalin and neomycin as previously described. ${ }^{50,51}$ ARRIVE guidelines for reporting animal research were taken into consideration in the reporting of the experiments.

Recombinant TTR production and purification. Recombinant mouse and human TTR were produced in a bacterial expression system using Escherichia coli BL21 and purified as previously described. ${ }^{52}$ Briefly, after growing the bacteria, the protein was isolated and purified by preparative gel electrophoresis after ionexchange chromatography. Protein concentration was determined using the Lowry method.

Recombinant GST-RAP production and purification. Recombinant GST-RAP production was previously described. ${ }^{22}$ Briefly, expression of the GSTRAP (pGEX-RAP) was induced by treating an Escherichia coli BL21 culture in the exponential phase of growth $(A 600 \mathrm{~nm}=0.4-0.5)$ with $0.5 \mathrm{mM}$ isopropyl $\beta$-D-thiogalactoside for $4-6 \mathrm{~h}$ at $30^{\circ} \mathrm{C}$. The protein, with an apparent molecular mass of 65KDa (GST (25 KDa)+ RAP (39KDa)) in a SDS-PAGE gel, was extracted and purified from the bacterial pellet through affinity chromatography on glutathione Sepharose 4B (GE Healthcare, Little Chalfont, UK), according to the manufacturer's recommendations.

Endotoxin removal. To remove endotoxins from recombinant TTR and GST-RAP, a polymixin B column (Thermo Scientific, Waltham, MA, USA) was used. Briefly, the column was regenerated with $1 \%$ sodium deoxycholate (Sigma, St Louis, $\mathrm{MO}$, USA) and washed with pyrogen-free buffer to remove detergent. Recombinant TTR was applied to the column and incubated during $1 \mathrm{~h}$ at room temperature. Aliquots of pyrogen-free buffer were added and the flow-through was collected. Protein concentration was determined using the Bradford method.

Primary hippocampal neuronal cultures. Primary cultures of mouse hippocampal neurons were prepared from the hippocampus of E17-E18 of WT, TTR KO and megalin $(+/-) /(+/+)$ TTR KO mice embryos (129/svJ background), as previously described. ${ }^{29,53}$ Neuronal cultures were maintained in serum-free Neurobasal medium (Gibco, Life Technologies, Carlsbad, CA, USA), supplemented with B27 (Gibco, Life Technologies), glutamate $(25 \mu \mathrm{M})$, glutamine $(0.5 \mathrm{mM})$ and gentamicin $(0.12 \mathrm{mg} / \mathrm{ml})$. Cells were kept at $37^{\circ} \mathrm{C}$ in a humidified incubator with $5 \%$ $\mathrm{CO} 2 / 95 \%$ air, for $24 \mathrm{~h}$, for the neurite outgrowth experiments or 7 days for the western blot experiments, the time required for maturation of hippocampal neurons. Cells were cultured at a density of $90000 \mathrm{cells} / \mathrm{cm}^{2}$ or $80000 \mathrm{cells} / \mathrm{cm}^{2}$ on poly-D-

Figure 4 TTR KO hippocampal neurons are more sensitive to an excitotoxic insult, than WT counterparts. TTR KO and WT cultured hippocampal neurons (7 DIV) were subjected to excitotoxic stimulation with glutamate ( $125 \mu \mathrm{M}$ glutamate, $20 \mathrm{~min}$ ) and further incubated in culture-conditioned medium $(14 \mathrm{~h}) . \mathrm{MAP}_{2}(\mathbf{b}, n=6)$ and Tau (d, $\left.n=5\right)$ protein levels were determined by western blot at the indicated time points after excitotoxic stimulation. The results are the average \pm S.E.M. of four to five independent experiments. Representative images of $\mathrm{MAP}_{2}$ (a) and Tau (c) are shown. GFP-transfected TTR KO and WT cultured hippocampal neurons (7 DIV) were also subjected to excitotoxic stimulation with glutamate. An immunocytochemistry against GFP was performed; the images are shown in (e), representative of four independent experiments. Cell survival was also assessed $14 \mathrm{~h}$ after the excitotoxic insult, using the fluorescent dye Hoechst 33342 (f, the representative image; $\mathbf{g}, \mathrm{WT} n=3, \mathrm{TTR} \mathrm{KO} n=4$ ). The results are the average \pm S.E.M. of three to four independent experiments. ( $h$ and i) TTR KO cultured hippocampal neurons (7 DIV) were subjected to excitotoxic stimulation with glutamate (125 $\mu \mathrm{M}$ glutamate, $20 \mathrm{~min}$ ) and further incubated in culture-conditioned medium with recombinant mouse TTR (300 $\mu \mathrm{g} / \mathrm{ml})$ for $14 \mathrm{~h}$, and stained for MAP 2 (h). Neurite number and neurite sum length were quantified using ImageJ software (i). The results are the average \pm S.E.M. of three independent experiments. Using the same experimental design as in (h), MAP 2 and Tau protein levels were also assessed by western blot, for the TTR KO cultured hippocampal neurons (j, $n=4)$. Statistical analysis was performed using one-way ANOVA followed by Bonferroni's multiple comparison test performed for each condition or Student's unpaired $t$-test for two-groups only analysis. ${ }^{* \star *} P<0.001,{ }^{* \star} P<0.01$, ${ }^{*} P<0.05$, n.s., not significant as compared with the control or as indicated. All the scale bars presented correspond to $50 \mu \mathrm{m}$ 
a
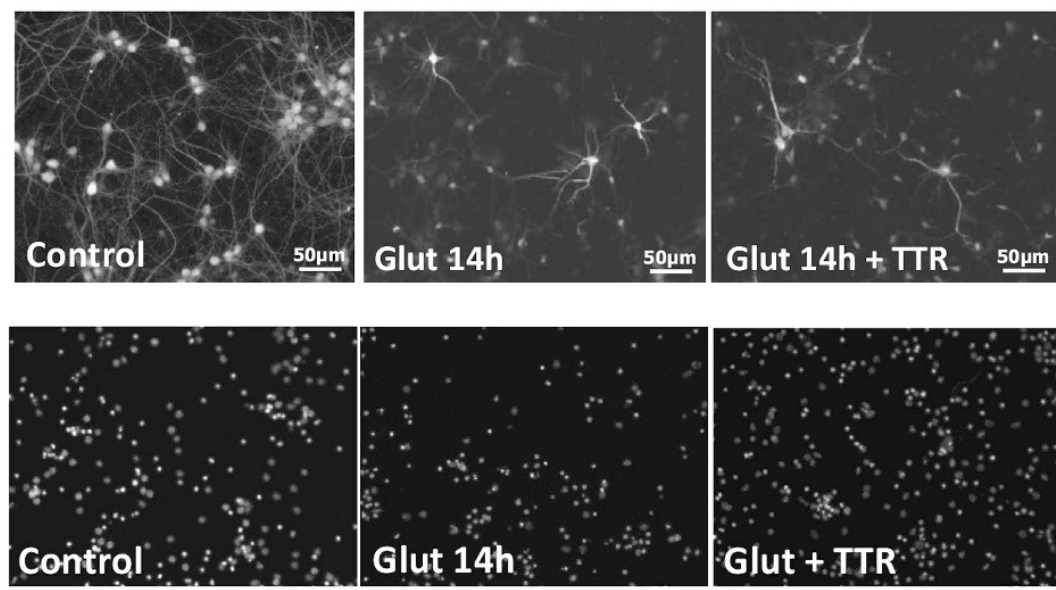

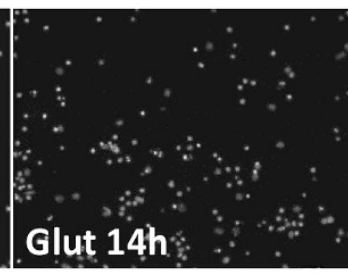

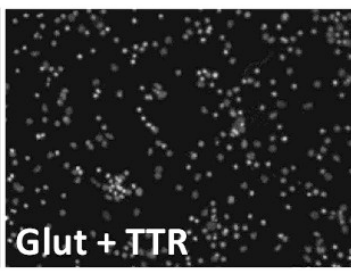

$\operatorname{Meg}(+/-)$

KO TTR
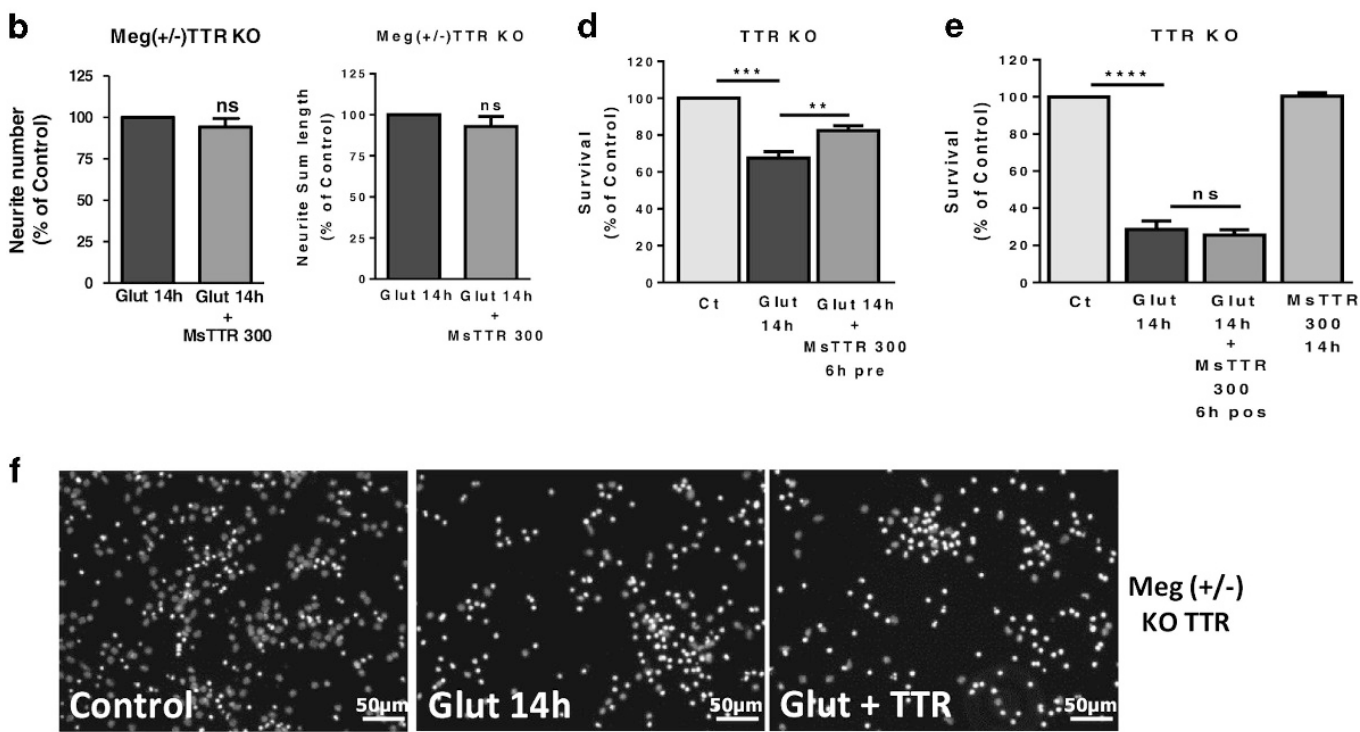

Meg $(+/+)$

KO TTR

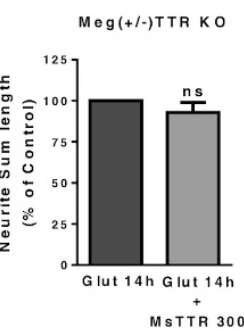

g
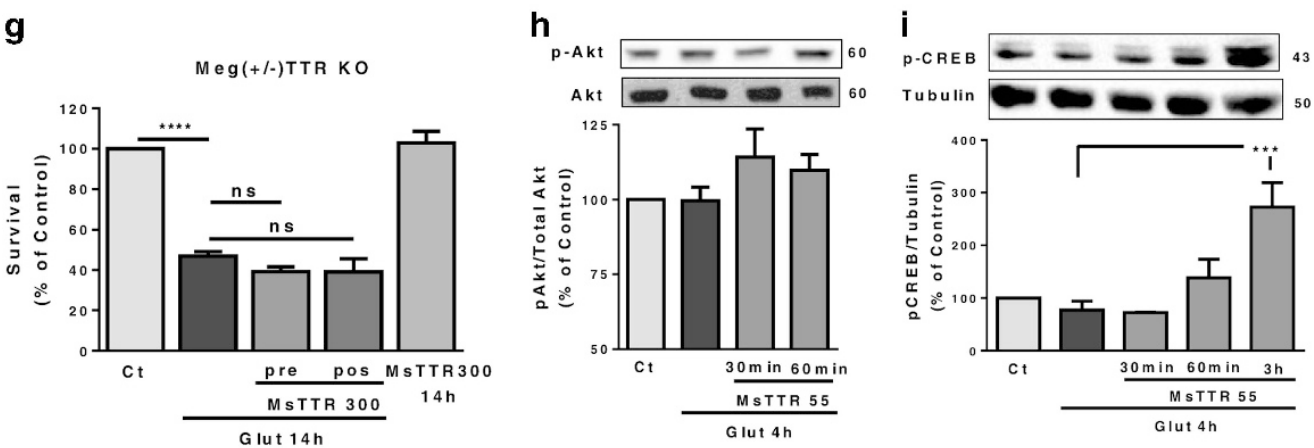

$\operatorname{Meg}(+/-)$

KO TTR
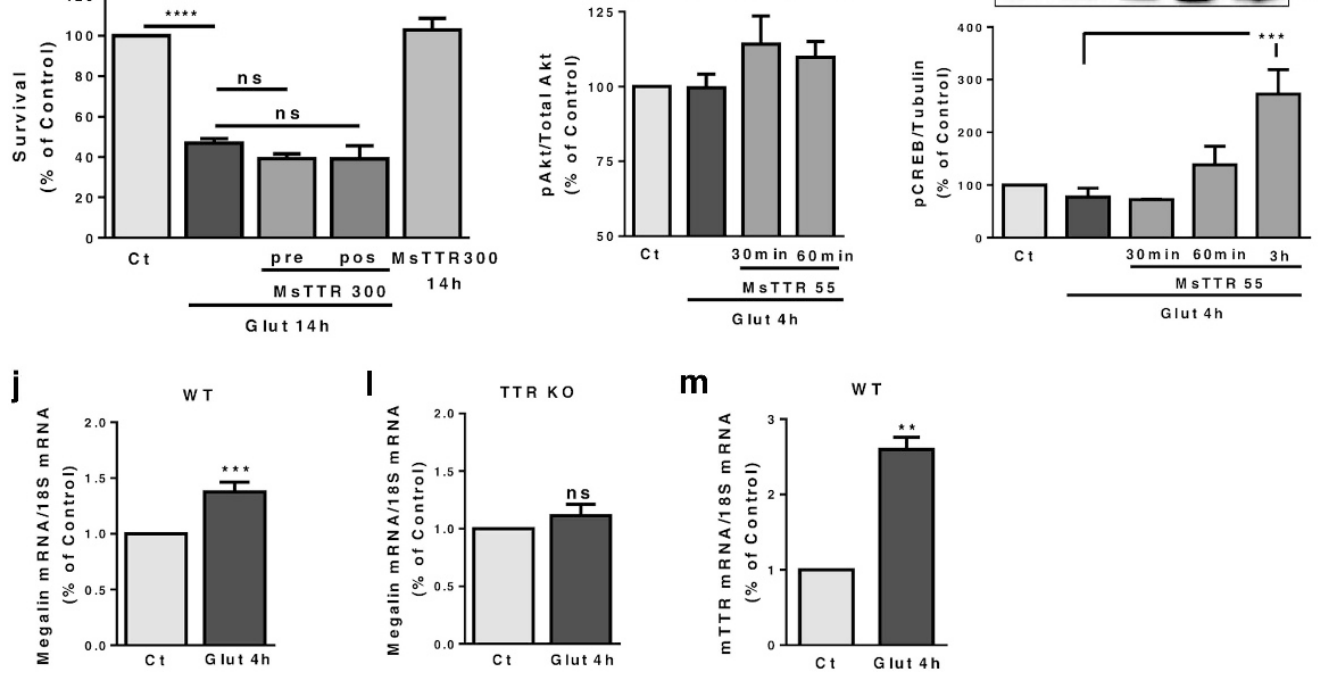


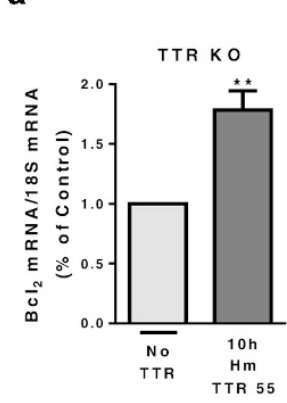

b

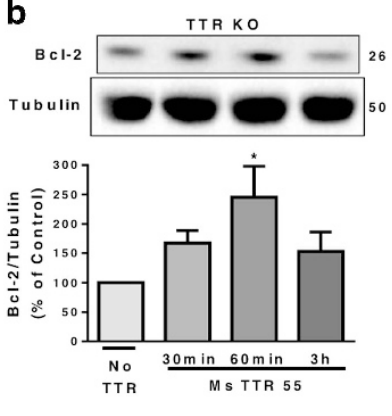

c

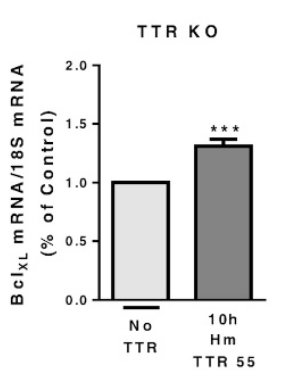

d

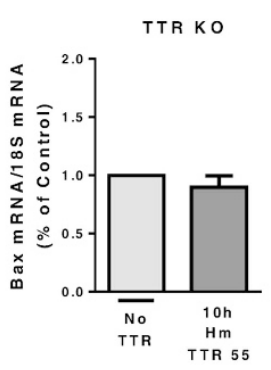

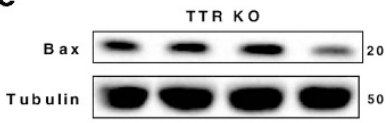

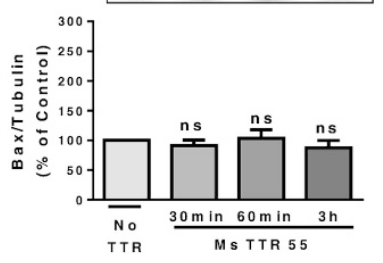

f
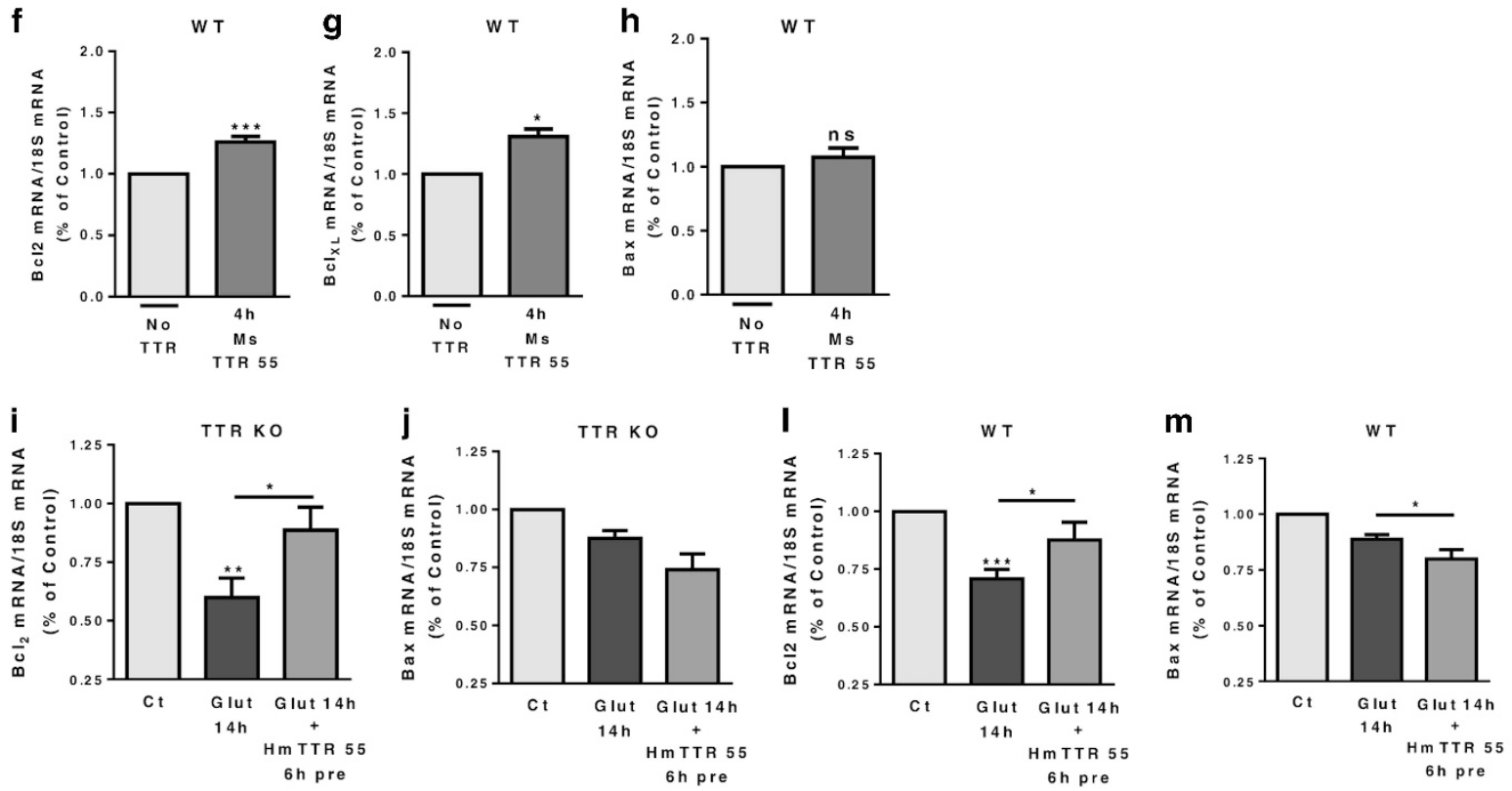

Figure 6 TTR neuroprotection involves the activation of anti-apoptotic signaling pathways. TTR KO cultured hippocampal neurons (7 DIV) were stimulated with recombinant mouse/human TTR ( $55 \mu \mathrm{g} / \mathrm{ml})$ in culture-conditioned medium. Anti-apoptotic proteins levels were accessed. Bcl2 mRNA levels $(\mathbf{a}, n=5)$ and protein levels (b, $n=6-8)$ and BclXL mRNA levels $(\mathbf{c}, n=4)$. The results are the average \pm S.E.M. of four to eight independent experiments. Pro-apoptotic levels of Bax were also accessed by analysis of mRNA $(\mathbf{d}, n=4)$ and protein levels $(\mathbf{e}, n=5-7)$. The results are the average \pm S.E.M. of four to seven in independent experiments. WT cultured hippocampal neurons (7 DIV) were also stimulated with recombinant mouse TTR ( $55 \mu \mathrm{g} / \mathrm{ml})$ and the mRNA of Bcl2 protein family members were accessed: Bcl2 (f, $n=4), \mathrm{BclXL}(\mathbf{g}, n=3)$ and Bax (h, $n=4)$. To address TTR neuroprotective activity through the balance of anti-apoptotic signaling pathways, Bcl2 and Bax mRNA levels were quantified in excitotoxic conditions with/without human TTR pre-incubation ( $55 \mu \mathrm{g} / \mathrm{ml})$ in TTR KO cultured hippocampal neurons (7 DIV) (i, $n=4 ; \mathbf{j}, n=3)$ and WT cultured hippocampal neurons $(7 \mathrm{DIV})(\mathbf{I}, n=3-5 ; \mathbf{m}, n=3-5)$. The results are the average \pm S.E.M. of three to six independent experiments. Statistical analysis was performed using one-way ANOVA followed by Bonferroni's multiple comparison test performed for each condition or Student's unpaired $t$-test for two-group comparisons. ${ }^{\star \star \star}{ }^{\star \star} P<0.001,{ }^{\star \star} P<0.01,{ }^{\star} P<0.05$, n.s., not significant as compared with the control or as indicated

Figure 5 TTR promotes neuronal survival, through a megalin-dependent manner. (a) Megalin $(+/-)$ TTR KO cultured hippocampal neurons (7 DIV) were subjected to excitotoxic stimulation with glutamate (125 $\mu \mathrm{M}$ glutamate, $20 \mathrm{~min}$ ) and further incubated in culture-conditioned medium with recombinant mouse TTR (300 $\mu \mathrm{g} / \mathrm{ml})$ for $14 \mathrm{~h}$, and stained for $\mathrm{MAP}_{2}$. Representative images are shown (a) and neurite number and neurite sum length were quantified with ImageJ software (b). The results are the average \pm S.E.M. of nine independent experiments. (c) TTR KO cultured hippocampal neurons (7 DIV) were subjected to excitotoxic stimulation with glutamate (125 $\mu \mathrm{M} \mathrm{glutamate,} 20$ min), with a $6 \mathrm{~h}$ pre-incubation with recombinant mouse TTR $(300 \mu \mathrm{g} / \mathrm{ml})$ in culture-conditioned medium. Cell survival was accessed $14 \mathrm{~h}$ after the excitotoxic insult, using the fluorescent dye Hoechst 33342 (c, representative images; d). The results are the average \pm S.E.M. of five independent experiments. In (e), a similar experimental design as in (b) was used, but adding mouse TTR $(300 \mu \mathrm{g} / \mathrm{ml})$ after the excitotoxic stimulus. The results are the average \pm S.E.M. of four independent experiments. (g) Using the same approach used as in (d) and (e), but using megalin (+l - )TTR KO cultured hippocampal neurons (7 DIV), mouse TTR ( $300 \mu \mathrm{g} / \mathrm{ml})$ was added before and after the excitotoxic stimulus. The results are the average \pm S.E.M. of five independent experiments (f). To address TTR signaling activity after the excitotoxic stimulation, mouse TTR was added to TTR KO hippocampal cultures (7 DIV), $4 \mathrm{~h}$ after a glutamate stimulus (125 $\mu \mathrm{M}$ glutamate, $20 \mathrm{~min}$ ) and Akt (Ser473) $(\mathrm{h}, n=3)$ and CREB phosphorylation (Ser133) (i, $n=3-5)$ were analyzed by western blot at several time points (30 min, $60 \mathrm{~min}, 3 \mathrm{~h}$ ). Megalin mRNA levels were also accessed after an excitotoxic insult (125 $\mu \mathrm{M}$ glutamate, 20 min) in WT cultured hippocampal neurons ( $7 \mathrm{DIV})(\mathrm{j}, n=5)$ and in TTR KO cultured hippocampal neurons (7 DIV) $(\mathrm{I}, n=9)$. TTR mRNA levels were also analyzed after an excitotoxic insult (125 $\mu \mathrm{M}$ glutamate, $20 \mathrm{~min})$ in WT cultured hippocampal neurons (7 DIV) $(\mathrm{m}, n=4)$. The results are the average \pm S.E.M. of four to five independent experiments. Statistical analysis was performed using one-way ANOVA followed by Bonferroni's multiple comparison test performed for each condition as compared with the control or as indicated or Student's unpaired $t$-test for two-groups only analysis. ${ }^{* \star} P<0.001,{ }^{* \star} P<0.01,{ }^{*} P<0.05$, n.s., not significant. All the scale bars presented correspond to $50 \mu \mathrm{m}$ 
a
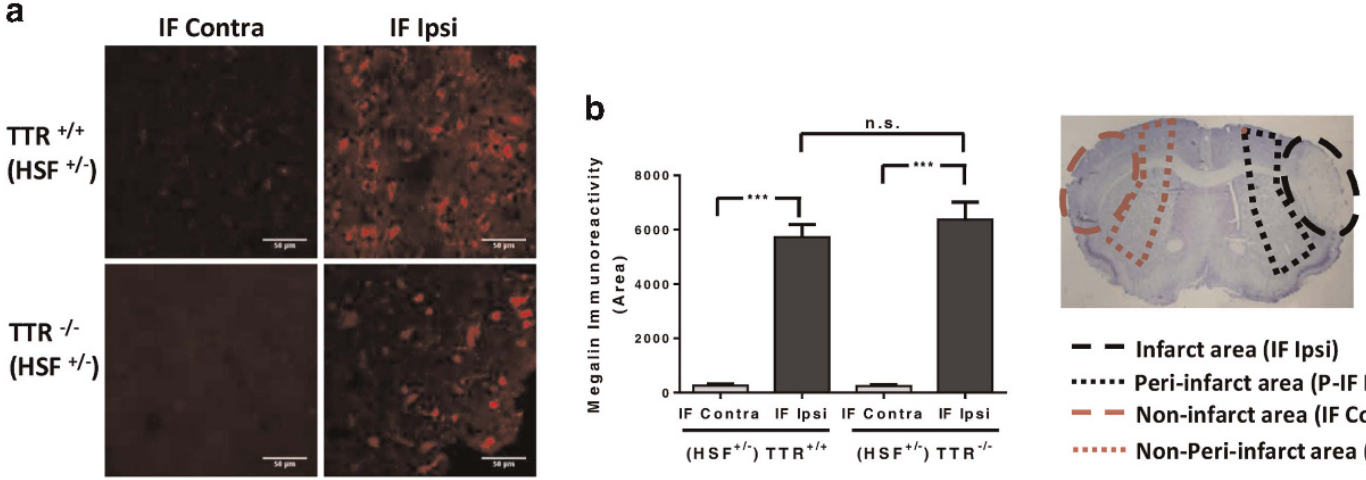

- - Infarct area (IF Ipsi)

...... Peri-infarct area (P-IF Ipsi)

- Non-infarct area (IF Contra)

...... Non-Peri-infarct area (P-IF Contra)

c
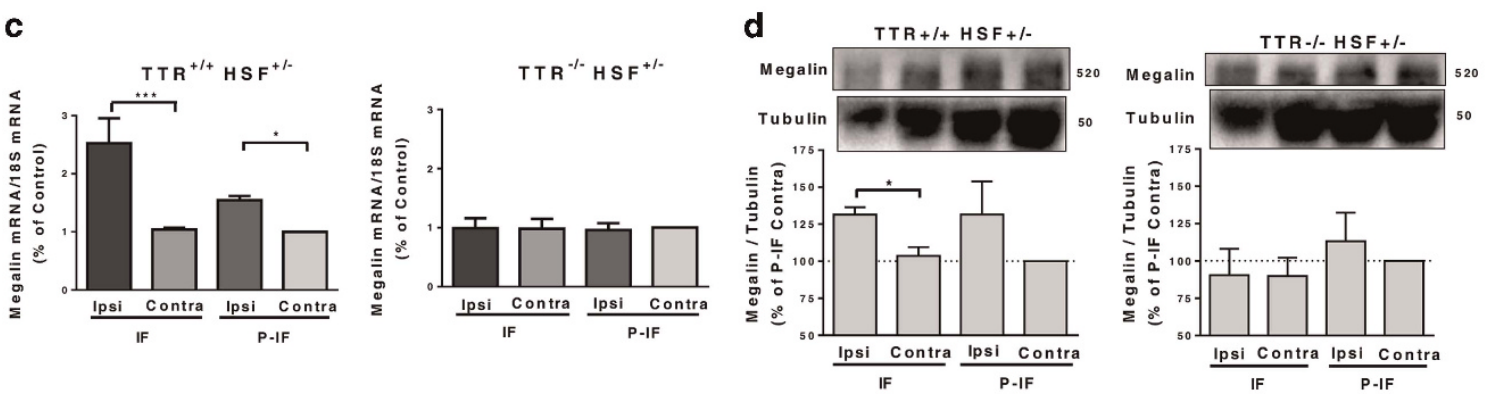

f
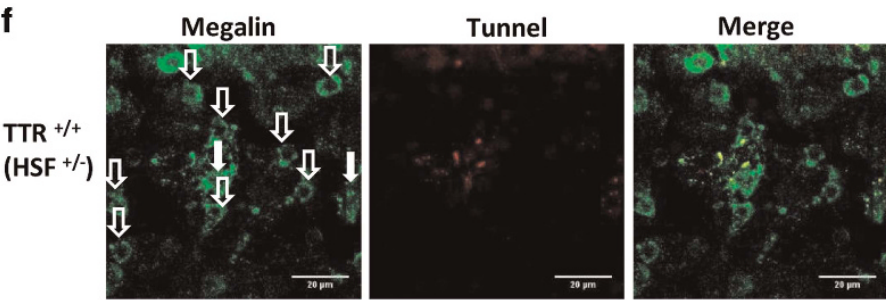
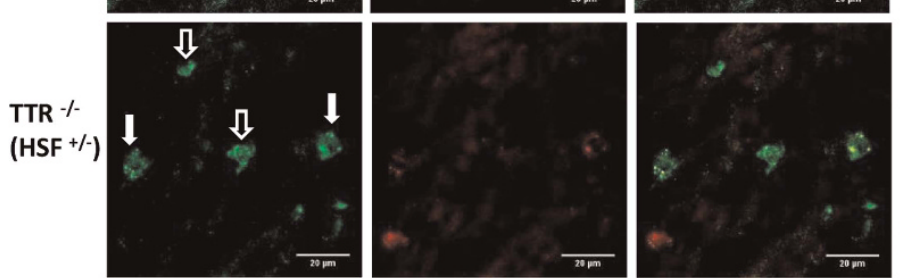

\section{g}
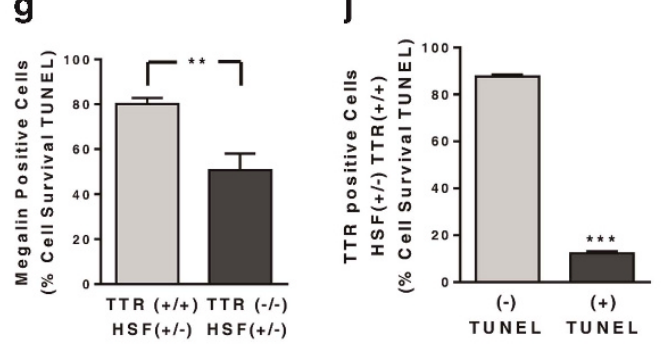

h
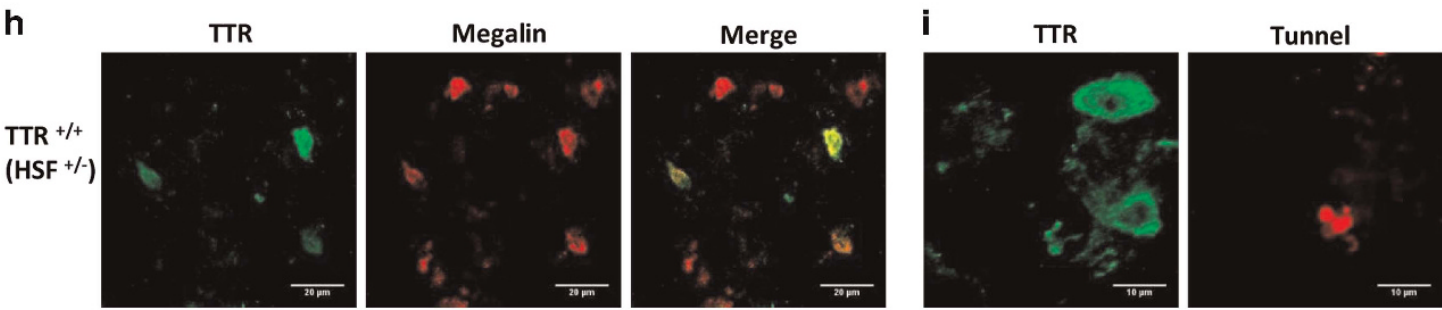

e

Megalin
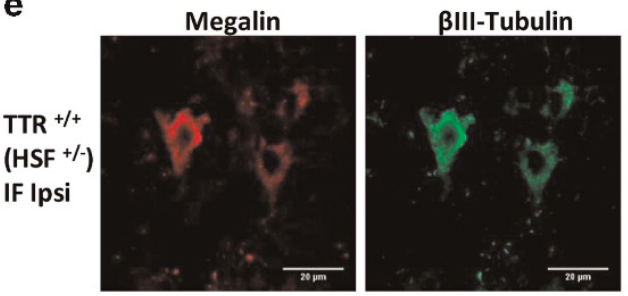

Merge

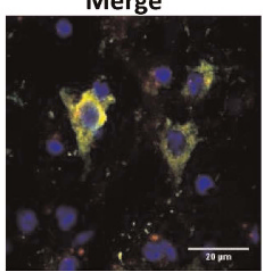


lysine-coated 6-well microplates (MW6) (for western blot and real-time PCR experiments) or glass coverslips (for immunocytochemistry studies), respectively. Megalin $(+/-)$ TTR KO mice embryos were all genotyped ( $5 \mathrm{~h}$ express protocol) to separate the megalin $(+/-)$ from the $(+/+)$. Meanwhile, hippocampi were hibernated using Hibernate E medium (Gibco, Life Technologies, Carlsbad, CA, USA) supplemented with diluted 1:10 B27 (Gibco, Life Technologies) and kept at $4^{\circ} \mathrm{C}$. The hippocampal neurons were cultured using a serum-free medium (B27), which does not contain T4 or RBP - TTR ligands. The following pre-established exclusion criteria were used: cell cultures with high \% of cell death (>30\%) and/or neurite network undeveloped or damaged. For the SKI-1 (Src kinase inhibitor I, Abcam (Cambridge, UK), ab120839, $200 \mathrm{nM}$ ) experiments, cells were pre-incubated with the inhibitor for $15 \mathrm{~min}$ and stimulated with TTR $(55 \mu \mathrm{g} / \mathrm{ml})$ in the presence or absence of the drug, for the time mentioned, at $37^{\circ} \mathrm{C}$. Regarding RAP (receptor-associated protein; LRP inhibitor, custom expressed, $350 \mu \mathrm{g} / \mathrm{ml}$ ) experiments, cells were pre-incubated with the inhibitor for $30 \mathrm{~min}$ and then stimulated with TTR $(55 \mu \mathrm{g} / \mathrm{ml})$ in the presence or absence of the protein, for the time mentioned, at $37^{\circ} \mathrm{C}$.

Neurite outgrowth analysis. Cultured hippocampal neurons from WT, TTR $\mathrm{KO}$ or megalin $(+/-)$ TTR KO mice embryos were isolated under the abovedescribed conditions, plated on poly-D-lysine-coated glass coverslips at a density of $5 \times 10^{4} \mathrm{cells} / \mathrm{cm}^{2}$. Recombinant mouse/human TTR $(55 \mu \mathrm{g} / \mathrm{ml}$ and $300 \mu \mathrm{g} / \mathrm{ml})$ was added to cell culture medium immediately after plating. Cells were maintained in culture during $24 \mathrm{~h}$, approximately, in order to allow the precise tracing of all the neurites per neuron. Longer days in vitro do not allow precise neurite quantification per neuron. Neurite outgrowth assay was also performed in 7 DIV TTR KO and megalin $(+/-)$ TTR KO cultures, after an excitotoxic stimulus, which allowed the neurite quantification. Cells were fixed with $4 \%$ paraformaldehyde and immunofluorescence was performed against $\mathrm{MAP}_{2}(1: 800, \mathrm{Abcam})$. The coverslips were mounted in a fluorescent mounting medium (DAKO, Glostrup, Denmark) and imaging was performed on a Zeiss (Oberkochen, Germany) Axiolmager Z1microscope, using a $\times 20$ oil objective. Between 15 and 20 pictures were randomly taken throughout the coverslip, in a blinded manner, for each condition. For the experiments involving the TTR antibody, TTR was pre-incubated $1 \mathrm{~h}$ at $37^{\circ}$ $C$ with the antibody, before being added to the cultures. Regarding RAP experiments, RAP $(350 \mu \mathrm{g} / \mathrm{ml})$ was added $30 \mathrm{~min}$ before TTR was added to the cultured neurons, after plating. Morphological measurements of neurite outgrowth were performed using the plugin NeuronJ from the ImageJ software..$^{54}$ Number and sum length of neurites per cell were the analyzed parameters. At least 60-80 cells were counted for each experimental condition in a blinded manner, and the experiments were repeated in more than three independent preparations. The experimental unit in these assays was each individual culture (with more than 60 neurons analyzed in each individual culture).

Cell death assay. Hippocampal neurons were cultured for 7 days on poly-Dlysine-coated glass coverslips as previously described. After the experiments, cells were fixed in $4 \%$ sucrose $/ 4 \%$ paraformaldehyde (in PBS). The cells were washed twice with PBS and incubated with Hoechst $33342(0.5 \mu \mathrm{g} / \mathrm{ml})$ to stain nuclei. Analysis of the nuclear morphology was performed on Zeiss Axiolmager Z1 florescence microscope, under a $\times 40$ oil objective. Live and dead cells were counted in a blinded manner, as performed for neurite outgrowth analysis, using ImageJ. The experimental unit in these assays was each individual culture (always performed with different breeding females in independent neuronal culture isolation procedures).

Western blot analysis. Cultured hippocampal neurons and dissected brain areas from pMCAO mice were homogenized in lysis buffer containing $20 \mathrm{mM}$ MOPS, $2 \mathrm{mM}$ EGTA, $5 \mathrm{mM}$ EDTA, $30 \mathrm{mM}$ sodium fluoride, $60 \mathrm{mM}$ glycerophosphate, $20 \mathrm{mM}$ sodium pyrophosphate, $1 \mathrm{mM}$ sodium orthovanadate, $1 \mathrm{mM}$ phenylmethylsulphonyl fluoride, $1 \%$ Triton $\mathrm{X}-100$ and $1 \times$ protease inhibitors mixture (GE Healthcare). Total protein concentration was determined using the Bradford method. Fifty micrograms of protein were applied and separated by $4 \% / 10 \%$ Tris-Glycine SDS-PAGE (or 3\%/7\% Tris-Acetate polyacrylamide gels for megalin) and transferred to a nitrocellulose Hybond-C membrane (GE Healthcare), using a wet system, with Tris/Glycine/SDS buffer (Bio-Rad, Hercules, CA, USA). Membranes were blocked at least $1 \mathrm{~h}$ at room temperature in blocking buffer, $5 \%$ bovine serum albumin in phosphate-buffered saline Tween 20 (PBST), and then incubated overnight a $4^{\circ} \mathrm{C}$ with primary antibodies diluted in blocking buffer, namely sheep megalin (1:1000; custom made), rabbit megalin (1:750, Abcam, ab129198), rabbit LRP1 (1:5000, Abcam, ab92544), rabbit Bax (1:1000, Cell Signaling (Danvers, MA, USA), \#2772), rabbit Bcl2 (1:1000, Cell Signaling, \#2870), rabbit phospho-Akt (Ser473, 1:1000, Cell Signaling, \#4060), rabbit Akt (1:1000, Cell Signaling, \#9272), rabbit phospho-p44/42 MAPK (1:1000, Cell Signaling, \#9101), rabbit p44/42 MAPK (1:1000, Cell Signaling, \#9102), rabbit phospho-CREB (Ser133, 1:1000, Cell Signaling, \#9198), rabbit CREB (1:1000, Cell Signaling, \#9197), rabbit phospho-Src (Tyr416, 1:1000, Cell Signaling, \#6943), mouse Src (1:1000, Cell Signaling, \#2110), rabbit anti-MAP2 (1:800; Abcam, ab24640), mouse anti-Tau (1:750, Cell Signaling, \#4019), mouse $\alpha$-tubulin (1:10 000, Sigma, T8203). Membranes were then incubated with anti-rabbit IgG-HRP (1:10 000, Binding Site, Birmingham, UK) and anti-mouse lgG-HPR (1:5000, Binding Site), for $1 \mathrm{~h}$ at room temperature. Blots were developed using Immun-Star WesternC Chemiluminescent kit (Bio-Rad) and exposed to Bio-Rad ChemiDoc XRS system or ECL Hyperfilm (GE Healthcare), if signal was too low. Quantitative analyses were performed using the Quantity One software or ImageLab from Bio-Rad Laboratories. The experimental unit in western blot assays was each individual culture (always performed with different breeding females in independent neuronal culture isolation procedures)

mRNA semi-quantification through real-time PCR. Total RNA was extracted from either 7 DIV cultured hippocampal neurons or dissected brain areas from pMCAO mice using TRIzol Reagent (Thermo Fisher Scientific, Waltham, MA, USA), as previously described. ${ }^{55}$ RNA quality and integrity was assessed using the Experion automated gel electrophoresis system (Bio-Rad, Hercules, CA, USA), as previously described. ${ }^{55}$ Samples showing RNA degradation or contamination by DNA were discarded. RNA concentration was determined using NanoDrop 1000 (Thermo Scientific). The samples were aliquoted and stored at $-80^{\circ} \mathrm{C}$ until further use. cDNA synthesis was performed using $1 \mu \mathrm{g}$ of total RNA and the SuperScript cDNA synthesis (Life Technologies, Carlsbad, CA, USA), as previously described. ${ }^{55}$ Samples were stored at $-80^{\circ} \mathrm{C}$ until further use. Primers used for real-time PCR were designed using 'Beacon Designer' software (Premier Biosoft International,

\footnotetext{
Figure 7 TTR neuroprotection in vivo (pMCAO) is also megalin-dependent. (a) Megalin levels after pMCAO were accessed by immunofluorescence confocal stacks of the different brain areas of wild-type and TTR KO mice (HSF+l - background) after $24 \mathrm{~h}$ of pMCAO. Representative immunofluorescence confocal stack of megalin in infarct area (IF Ipsi) and contralateral area (IF Contra) (scale bar $50 \mu \mathrm{m}$ ). (b) The semi-quantification results are the average \pm S.E.M. of three to five stacks/animal (three animals for each phenotype). (c) Megalin mRNA levels were quantified for the different brain areas (IF Contra versus IF Ipsi; P-IF Contra versus P-IF Ipsi) of the $24 \mathrm{~h} \mathrm{pMCAO} \mathrm{WT} \mathrm{and} \mathrm{TTR} \mathrm{KO} \mathrm{mice}$ (HSF $+/$ - background). The results are the average \pm S.E.M. of three to four different animals for each phenotype. (d) Megalin protein levels were quantified for the different brain areas (IF Contra versus IF Ipsi) of the $24 \mathrm{~h} \mathrm{pMCAO} \mathrm{WT} \mathrm{and} \mathrm{TTR} \mathrm{KO} \mathrm{mice} \mathrm{(HSF+l} \mathrm{-} \mathrm{background).} \mathrm{The} \mathrm{results} \mathrm{are} \mathrm{the} \mathrm{average} \pm$ S.E.M. of three different animals for each phenotype. (e) Representative images of megalin immunofluorescence confocal stacks of live cells co-localizing with $\beta$ Ill-tubulin from the infarct area of WT mice (HSF $+/-$ background) after $24 \mathrm{~h} \mathrm{pMCAO}$ (three animals). ( $f$ and $\mathbf{g}$ ) Semi-quantification of the cell survival accessed with TUNEL reaction assay from the megalin-positive cells in the infarct area of TTR KO and WT mice (HSF+l - background) after $24 \mathrm{~h}$ pMCAO. The results are the average \pm S.E.M. of five to six stacks from three animals for each phenotype (f, representative image; g). (h) Representative immunofluorescence confocal stack of TTR-positive live cells co-localizing with megalin, from the infarct area of WT mice (HSF+l - background), after $24 \mathrm{~h} \mathrm{pMCAO} \mathrm{(three} \mathrm{animals).} \mathrm{(i} \mathrm{and} \mathbf{j})$ Semi-quantification of the cell survival from the TTR-positive cells in the infarct area of WT mice (HSF+l - background) after $24 \mathrm{~h} \mathrm{pMCAO}$. Cell survival was accessed with TUNEL reaction assay. The results are the average \pm S.E.M. of six stacks from three WT pMCAO animals (i, representative images; j). Statistical analysis was performed using one-way ANOVA followed by Bonferroni's multiple comparison test performed for each condition or Student's unpaired $t$-test for two-group comparisons. ${ }^{\star \star *} P<0.001,{ }^{\star \star} P<0.01,{ }^{*} P<0.05$, n.s., not significant as compared with the control or as indicated. Scale bar in (a and i) correspond to 50 and $10 \mu \mathrm{m}$, respectively. All the others (e,f and $\mathbf{h}$ ) correspond to $20 \mu \mathrm{m}$
} 
Palo Alto, CA, USA) as described previously. ${ }^{55}$ Oligonucleotides used for megalin real-time PCR were: forward 5'-GGCTCACTCAAGTCCGCATCTTCC-3' and reverse 5'-ACTCAACGGTGCTGCCAGTTACG-3'; for Bcl2: forward 5'-TGTGGA TGACTGAGTACCT-3' and reverse 5'-CAGAGACAGCCAGGAGAA-3'; for BcIXL: forward 5'-GCCACCTATCTGAATGACCA-3' and reverse 5'-GTTCCCGTAGAGA TCCACAAA-3'; for Bax: forward 5'-TAAAGTGCCCGAGCTGAT-3' and reverse $5^{\prime}$ CCGAAGTAGGAGAGGAGG-3'; for mTTR: forward 5'-AGCCCTTTGCCTCTGG

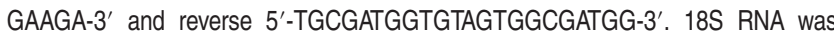
used as reference gene with the following primers: forward $5^{\prime}$-AAATCAGTTAT GGTTCCTTTGGTC-3' and reverse 5'GCTCTAGAATTACCACAGTTATCCAA3'. The annealing temperature was $60^{\circ} \mathrm{C}$. For gene expression analysis, $1 \mu \mathrm{l}$ of $1: 10$ diluted cDNA was added to $10 \mu \mathrm{l}$ of $2 \times$ SYBR Green Master Mix (Bio-Rad) and the final concentration of each primer was $250 \mathrm{nM}$ in $20 \mu$ l total volume. The thermocycling reaction was initiated by activation of Taq DNA Polymerase by heating at $95^{\circ} \mathrm{C}$ during $3 \mathrm{~min}$, followed by 45 cycles of a $15 \mathrm{~s}$ denaturation step at $95^{\circ} \mathrm{C}$ and a $20 \mathrm{~s}$ annealing/elongation step at $60^{\circ} \mathrm{C}$. The fluorescence was measured after the extension step, using the iQ5 Multicolor Real-Time PCR Detection System (BioRad). After the thermocycling reaction, the melting step was performed with slow heating, starting at $55^{\circ} \mathrm{C}$ and with a rate of $0.5^{\circ} \mathrm{C}$ per $10 \mathrm{~s}$, up to $95{ }^{\circ} \mathrm{C}$, with continuous measurement of fluorescence. Data analysis was performed using Pfaff method that adds the efficiency correction (amplification efficiencies of transcripts) to the $\triangle \mathrm{CP}$ (between target gene and reference gene).$^{56}$ Results were normalized with 18S RNA as internal reference gene, because it showed a stable expression in the conditions tested (compared with other reference genes tested). Efficiency correction was carried out for all the independent experiments, in all PCR plates. The experimental unit in QPCR was each individual culture (always performed with different breeding females in independent neuronal culture isolation procedures).

Transfection. The expression vector containing the GFP gene was the pEGFP-N1 vector (BD Biosciences Clontech, San Jose, CA, USA). The plasmid sequence of pEGFP-N1 was verified by DNA sequencing reactions. Transfection of cultured hippocampal neurons with GFP and yellow cameleon-Nano15 was performed by the calcium phosphate co-precipitation method as previously described, with minor modifications. ${ }^{53}$ Briefly, $2 \mu \mathrm{g}$ of plasmid DNA were diluted in Tris-EDTA (TE) pH 7.3 and mixed with HEPES calcium chloride pH $7.2(2.5 \mathrm{M}$ $\mathrm{CaCl} 2,10 \mathrm{mM}$ HEPES). This DNA/TE/Calcium mix was added to an $2 \times$ HEPESbuffered saline solution $(270 \mathrm{mM} \mathrm{NaCl}, 10 \mathrm{mM} \mathrm{KCl}, 1.4 \mathrm{mM} \mathrm{Na} 2 \mathrm{HPO} 4,11 \mathrm{mM}$ Dextrose, $42 \mathrm{mM}$ HEPES), $\mathrm{pH}$ 7.2. The precipitates were allowed to form for $30 \mathrm{~min}$, with vortex mixing every $5 \mathrm{~min}$, to ensure that the precipitates had similar small sizes. Meanwhile, coverslips with cultured neurons were incubated with cultured conditioned medium with $2 \mathrm{mM}$ of kynurenic acid. The precipitate was added drop wise to each coverslip and incubated at $37^{\circ} \mathrm{C}, 5 \% \mathrm{CO}_{2}$, for $3 \mathrm{~h}$. Cells were then washed with acidic $\left(10 \% \mathrm{CO}_{2}\right)$ equilibrated culture medium containing $2 \mathrm{mM}$ kynurenic acid and returned to the $37^{\circ} \mathrm{C} / 5 \% \mathrm{CO}_{2}$ incubator for $15 \mathrm{~min}$. Finally, the medium was replaced with the initial culture-conditioned medium, and the cells were further incubated in a $37{ }^{\circ} \mathrm{C} / 5 \% \mathrm{CO}_{2}$ incubator for $48 \mathrm{~h}$ to allow protein expression.

Immunocytochemistry. Cells were fixed in $4 \%$ sucrose/paraformaldehyde and permeabilized with $0.3 \%$ Triton X-100 in PBS. Neurons were then incubated with $5 \%$ bovine serum albumin (Sigma) in PBS $+0.1 \%$ Tween 20 , for $1 \mathrm{~h}$ at $37^{\circ} \mathrm{C}$, to block nonspecific binding, and incubated with primary antibodies, overnight at $4{ }^{\circ} \mathrm{C}$ Cells were then washed five times with PBS+ $0.1 \%$ Tween+ $0.5 \%$ bovine serum albumin and incubated with the appropriate secondary antibodies, for $1 \mathrm{~h}$ at $37^{\circ} \mathrm{C}$ The coverslips were mounted in a fluorescent mounting medium (DAKO) and imaging was performed on a laser scanning Confocal Microscope Leica (Wetzlar, Germany) SP2 AOBS SE, using the $\times 40 / \times 63$ oil objective. Primary antibodies used were anti-GFP (1:250, Santa Cruz, Dallas, TX, USA), anti-megalin (1:200, Biorbyt (Cambridge, UK), orb6173), anti-MAP2 (1:800; Abcam, ab24640), anti-Tau (1:750, Cell Signaling, \#4019), as secondary antibodies Alexa Fluor 488 and 594 (1:750, Life technologies) were used. The fluorescent dye Hoechst $33342(0.5 \mu \mathrm{g} /$ $\mathrm{ml}-10 \mathrm{~min}$ room temperature) was used to stain nuclei.

Permanent middle cerebral artery occlusion - pMCAO. Focal cerebral ischemia was induced as described previously. ${ }^{57}$ Male mice were anesthetized subcutaneously with Hypnorm/Stesolid (fentanyl citrate $(0.315 \mathrm{mg} / \mathrm{ml}$; Jansen-Cilag, Barcarena, Portugal), Fluanisone $(10 \mathrm{mg} / \mathrm{ml}$; Jansen-Cilag) and Diazepamum (5 mg/ml; Dumex, Copenhagen, Denmark)) and placed on a $37^{\circ} \mathrm{C}$ heating pad. The left temporoparietal region of the head was shaved and a skin incision was made between the lateral part of the orbit and the external auditory meatus. The superior pole of the parotid gland was pushed downwards as was the upper part of the temporal muscle. A small craniotomy was made with a $0.7-\mathrm{mm}$ burr just over the MCA at the level of the inferior cerebral vein. The inner layer of the skull was removed with fine forceps, and the dura mater opened. The MCA was bipolarly electrocauterized applying forceps coupled to an electrosurgical unit (ICC50; Erbe, Tübingen, Germany). The incision was closed with a 4-0 nylon suture; $1 \mathrm{ml}$ of physiological saline solution $(9 \mathrm{~g} / \mathrm{l})$ was injected subcutaneously and the eyes coated with ointment to protect from drying. Before killing of the mice, they were kept in a recovery room at $28^{\circ} \mathrm{C}$ for $24 \mathrm{~h}$. Post-surgical pain treatment consisted of supplying the mouse subcutaneously with Temgesic $(0.001 \mathrm{mg} / 20 \mathrm{~g}$ buprenorphinum; Reckitt \& Colman, Hull, UK) every $8 \mathrm{~h}$ for the first $24 \mathrm{~h}$. Mice were killed by deeply anesthetizing with pentobarbital. The total number of animals used (all included in the analysis): three animals for each phenotype (WT, TTR KO, both $(\mathrm{HSF}(+/-)$ background)) were used for immunohistochemistry and four animals for each phenotype (WT, TTR KO, both $(\mathrm{HSF}(+/-)$ background)) for biochemical analysis. Western blot: After sacrifice, the brain was collected and $2 \mathrm{~mm}$ brain sections were excised with a $1 \mathrm{~mm}$ coronal mouse matrice. The slices were immediately frozen with dry ice and the ipsilateral and contralateral areas of the brain slices were taken using a Harris Unicore $2 \mathrm{~mm}$ tip (Pelco International, Redding, CA, USA). Samples were then homogenized and processed for western blot. Histochemistry: After mice were deeply anesthetized, they were transcardially perfused with ice-cold PBS followed by $4 \%$ paraformaldehyde in $0.1 \mathrm{M}$ phosphate buffer ( $\mathrm{pH}$ 7.4). The brains were removed, post-fixed in the same fixative overnight at $4{ }^{\circ} \mathrm{C}$ and then left in $30 \%$ sucrose in PBS at $4{ }^{\circ} \mathrm{C}$, until sinking in the solution. Coronal sections $(20 \mu \mathrm{m})$ were cut on a freezing microtome (Leica Cryostat CM 3050) and mounted on gelatin-chromium-covered glass slides. Sections were then used for immunohistochemistry analysis. The experimental unit in both western blot and histochemistry of pMCAO mice was each individual mice (in which the focal cerebral ischemia was performed in separate periods of time, with mice randomly selected in each phenotype (only by age and sex for the total group in experiment)).

Immunohistochemistry. Slides containing the brain slides from WT and TTR KO (HSF $(+/-)$ background) $24 \mathrm{~h}$ pMCAO were removed from freezer and incubated at room temperature for at least $15 \mathrm{~min}$. Then, the slides were incubated with Tris-buffer saline (TBS), and permeabilized with $0.2 \%$ Triton X-100 in TBS solution for $10 \mathrm{~min}$ and rinsed in TBS $0.025 \%$ Triton X-100. Blocking was performed with $10 \%$ fetal bovine serum, plus $1 \%$ bovine serum albumin and $0.3 \mathrm{M}$ glycine, in TBS, for $2 \mathrm{~h}$ at room temperature. Primary antibodies were always incubated overnight at $4^{\circ} \mathrm{C}$, in TBS $1 \%$ bovine serum albumin. Secondary antibodies were incubated $1 \mathrm{~h}$ at room temperature. The slides were mounted in a fluorescent mounting medium (DAKO) and imaging was performed on a laser scanning Confocal Microscope Leica SP2 or SP5 AOBS SE, using the $\times 40 / \times 63$ oil objective. In each set of experiments, the same batch of antibodies (primary and secondary) was used, and images were taken using the same settings, such as camera exposure times. For the cell survival semi-quantification (Figures $9 g$ and $j$ ), cells were counted, that is, either they expressed the indicated epitopes or not. Primary antibodies used were anti-mouse TTR (1:150, Rabbit, custom made), anti-megalin (1:1000, Sheep, custom made), anti- $\beta$ III-tubulin (1:500, monoclonal mouse, Promega, Madison, WI, USA, G712A), anti-BrdU (TUNEL Assay Kit, Abcam, ab66110); as secondary antibodies Alexa Fluor 488 and 568 (1:750, Life Technologies) were used. The fluorescent dye Hoechst $33342(0.5 \mu \mathrm{g} / \mathrm{ml}-15 \mathrm{~min}$ room temperature) was used to stain nuclei.

FRET assay-intracellular calcium concentration. Cells (TTR KO cultured neurons, $80000 \mathrm{cell} / \mathrm{s} / \mathrm{cm}^{2}$ ) were imaged in poly-D-lysine-coated glassbottom dishes (ibidi $\mathrm{GmbH}$, Martinsried, Germany) $48 \mathrm{~h}$ after transfection with yellow cameleon-Nano15 (YC-Nano15), an ultrasensitive $\mathrm{Ca}^{2+}$ FRET probe. ${ }^{27}$ This FRET probe has high calcium affinity, enabling the detection of subtle calcium changes associated with intracellular signaling dynamics and neuronal activity, even at the in vitro culture level. Cells were selected for the assay upon two parameters only: transfected with yellow cameleon-Nano15 and the ones that look healthy, with intact neurites. The plasmid was obtained from Addgene (Cambridge, MA, USA) (plasmid \#51961). Neuronal cultures were performed using a Neurobasal medium without phenol red (Gibco, Life Technologies) to optimize signal/noise levels. Recombinant TTR stimuli and chemical inhibitors were previously diluted in PBS and applied directly to the conditioned culture medium in the dish. Assays were performed under a humidified and heated chamber, for periods of $20 \mathrm{~min}$. Fluorescence imaging of cells was performed using an epifluorescence inverted 
microscope (DMl 6000B, Leica Microsystems) with a PlanApo $\times 63$ (N.A. 1.4) glycerol immersion objective. Data acquisition and processing was based on FerrazNogueira et al. ${ }^{58}$ Briefly, a mercury lamp coupled to a light attenuator (EL6000, Leica Microsystems) and a bandpass filter was used to excite directly the donor fluorescent protein. The cyan and yellow fluorescence signals were acquired using bandpass filters $(480 / 40 \mathrm{~nm}$ and $530 / 30 \mathrm{~nm}$ for cyan and yellow fluorescence, respectively). The setup used a 440/520-nm dichroic mirror (CG1, Leica Microsystems) and the bandpass filters were mounted in external filter wheels (Fast Filter Wheels, Leica Microsystems). The FRET/donor change was calculated using ImageJ software. Customized macros were used to subtract the background from raw images and to create intensity-modulated ratio images. The time axis in the plots was adjusted to consider the TTR administration time as ' $0 \mathrm{~s}$ ' (dashed line in the graphs), but first time analyzed after stimulation is ' $0.33 \mathrm{~s}$ '. Drugs and inhibitors used in this FRET assay were always pre-incubated for $15 \mathrm{~min}$ before TTR stimulation: SKI $(200 \mathrm{nM})$, kynurenic acid (2 mM, Sigma) and MK801 $(50 \mu \mathrm{M}$, Calbiochem, San Diego, CA, USA). NMDA (10 $\mu \mathrm{M}$, Sigma) was used to stimulate neurons, that is, NMDA receptors. The experiments performed without calcium or with $60 \mathrm{mM}$ of $\mathrm{KCl}$ used a Krebs-Ringer solution. The composition of the solution used in the experiment with $\mathrm{KCl}$ consisted of: $119 \mathrm{mM} \mathrm{NaCl}, 60 \mathrm{mM} \mathrm{KCl}, 1.0 \mathrm{mM}$ $\mathrm{NaH}_{2} \mathrm{PO}_{4}, 2.5 \mathrm{mM} \mathrm{CaCl}_{2} .2 \mathrm{H}_{2} \mathrm{O}, 1.3 \mathrm{mM} \mathrm{MgCl} 2.6 \mathrm{H}_{2} \mathrm{O}, 20 \mathrm{mM}$ HEPES and $11 \mathrm{mM}$ $\mathrm{D}$-glucose, $\mathrm{pH}$ 7.4. The solution of the experiment without calcium had the same composition with the exception of $\mathrm{KCl}$, which was present at a smaller concentration $(2.5 \mathrm{mM})$, and $\mathrm{CaCl}_{2}$, which was replaced with $2 \mathrm{mM} \mathrm{EGTA}$. The experimental unit in FRET assays was each individual neuron (four to six neurons were analyzed in each individual culture).

Statistical analysis. Protein values were normalized for $\alpha$-tubulin or nonphosphorylated forms of the protein in study, whereas mRNA transcripts were normalized for $18 \mathrm{~S}$ mRNA. Data are presented as mean \pm S.E.M. of at least three different experiments (exact number described in figure legends), performed in independent preparations. A previous power analysis was performed in order to obtain a $25 \%$ difference (with 10\% S.D.) among two groups, with $90-95 \%$ power and we obtain sample sizes of three to six animals or individual cultures. Statistical analysis of the results was performed using one-way analysis of variance (ANOVA) followed by Bonferroni multiple comparison test, when three groups were present: ${ }^{* * *} P<0.001,{ }^{* *} P<0.01,{ }^{*} P<0.05$, n.s. (not significant). Unpaired Student's $t$-test was used when the comparisons were only between two groups: ${ }^{* \star} P<0.001$, ${ }^{\star *} P<0.01,{ }^{*} P<0.05$, n.s. (not significant).

\section{Conflict of Interest}

The authors declare no conflict of interest.

Acknowledgements. This work was supported by FEDER funds through the Operational Competitiveness Programme - COMPETE, by national funding from the Portuguese Foundation for Science and Technology (FCT) under the projects FCOMP-01-0124-FEDER-022718 (PEST-c/SAU/LA0002/2011) FCT- FEDER for Unit 4293 in partnership with PT2020 and PTDC/SAU-OSM/64093/2006, a PhD fellowship (SFRH/BD/35982/2007) to Marta Vieira and post-doctoral fellowship (SFRH/ BPD/84178/2012) to João Gomes. We acknowledge Paul Moreira from IBMC for support in recombinant protein production and Paula Gonçalves from IBMC, for tissue processing. We would like to thank Professor Carlos Duarte (University of Coimbra) for the analysis of the paper and contributing with new ideas and helpful discussion.

1. Alshehri B, D'Souza DG, Lee JY, Petratos S, Richardson SJ. The diversity of mechanisms influenced by transthyretin in neurobiology: development, disease and endocrine disruption. J Neuroendocrinol 2015; 27: 303-323.

2. Fleming CE, Mar FM, Franquinho F, Saraiva MJ, Sousa MM. Transthyretin internalization by sensory neurons is megalin mediated and necessary for its neuritogenic activity. $J$ Neurosci 2009; 29: 3220-3232.

3. Santos SD, Lambertsen KL, Clausen BH, Akinc A, Alvarez R, Finsen B et al. CSF transthyretin neuroprotection in a mouse model of brain ischemia. J Neurochem 2010; 115: 1434-1444.

4. Gao C, Zhang B, Zhang W, Pu S, Yin J, Gao Q. Serum prealbumin (transthyretin) predict good outcome in young patients with cerebral infarction. Clin Exp Med 2011; 11: 49-54.

5. Quintela T, Goncalves I, Baltazar G, Alves CH, Saraiva MJ, Santos CR. 17beta-estradiol induces transthyretin expression in murine choroid plexus via an oestrogen receptor dependent pathway. Cell Mol Neurobiol 2009; 29: 475-483.
6. Wang X, Li W, Zhao D, Liu B, Shi Y, Chen B et al. Caenorhabditis elegans transthyretin-like protein TTR-52 mediates recognition of apoptotic cells by the CED-1 phagocyte receptor. Nat Cell Biol 2010; 12: 655-664.

7. Sousa MM, Saraiva MJ. Internalization of transthyretin. Evidence of a novel yet unidentified receptor-associated protein (RAP)-sensitive receptor. J Biol Chem 2001; 276: 14420-14425.

8. Sousa MM, Norden AG, Jacobsen C, Willnow TE, Christensen El, Thakker RV et al. Evidence for the role of megalin in renal uptake of transthyretin. J Biol Chem 2000; 275: 38176-38181.

9. Sousa MM, Yan SD, Stern D, Saraiva MJ. Interaction of the receptor for advanced glycation end products (RAGE) with transthyretin triggers nuclear transcription factor kB (NF-kB) activation. Lab Invest 2000; 80: 1101-1110.

10. Vieira M, Gomes JR, Saraiva MJ. Transthyretin induces insulin-like growth factor I nuclear translocation regulating its levels in the hippocampus. Mol Neurobiol 2015; 51: 1468-1479.

11. Alvira-Botero X, Perez-Gonzalez R, Spuch C, Vargas T, Antequera D, Garzon M et al, Megalin interacts with APP and the intracellular adapter protein FE65 in neurons. Mol Cell Neurosci 2010; 45: 306-315.

12. Marzolo MP, Farfan $P$. New insights into the roles of megalin/LRP2 and the regulation of its functional expression. Biol Res 2011; 44: 89-105.

13. Mantuano E, Mukandala G, Li X, Campana WM, Gonias SL. Molecular dissection of the human alpha2-macroglobulin subunit reveals domains with antagonistic activities in cell signaling. J Biol Chem 2008; 283: 19904-19911.

14. ladecola C, Anrather J. Stroke research at a crossroad: asking the brain for directions. Nat Neurosci 2011; 14: 1363-1368.

15. Schwamm LH, Ali SF, Reeves MJ, Smith EE, Saver JL, Messe S et al. Temporal trends in patient characteristics and treatment with intravenous thrombolysis among acute ischemic stroke patients at Get With The Guidelines-Stroke hospitals. Circ Cardiovasc Qual Outcomes 2013; 6: 543-549.

16. Lai TW, Zhang S, Wang YT. Excitotoxicity and stroke: identifying novel targets for neuroprotection. Prog Neurobiol 2014; 115: 157-188.

17. Hill MD, Martin RH, Mikulis D, Wong JH, Silver FL, Terbrugge KG et al. Safety and efficacy of NA-1 in patients with iatrogenic stroke after endovascular aneurysm repair (ENACT): a phase 2, randomised, double-blind, placebo-controlled trial. Lancet Neurol 2012; 11: 942-950.

18. Szydlowska K, Tymianski M. Calcium, ischemia and excitotoxicity. Cell Calcium 2010; 47: 122-129.

19. Ribeiro CA, Oliveira SM, Guido LF, Magalhaes A, Valencia G, Arsequell G et al. Transthyretin stabilization by iododiflunisal promotes amyloid-beta peptide clearance, decreases its deposition, and ameliorates cognitive deficits in an Alzheimer's disease mouse model. J Alzheimers Dis 2014; 39: 357-370.

20. Berni R, Malpeli G, Folli C, Murrell JR, Liepnieks JJ, Benson MD. The lle-84-> Ser amino acid substitution in transthyretin interferes with the interaction with plasma retinol-binding protein. J Biol Chem 1994; 269: 23395-23398.

21. Refetoff S, Dwulet FE, Benson MD. Reduced affinity for thyroxine in two of three structura thyroxine-binding prealbumin variants associated with familial amyloidotic polyneuropathy. J Clin Endocrinol Metab 1986; 63: 1432-1437.

22. Herz J, Goldstein JL, Strickland DK, Ho YK, Brown MS. 39-kDa protein modulates binding of ligands to low density lipoprotein receptor-related protein/alpha 2-macroglobulin receptor. J Biol Chem 1991; 266: 21232-21238.

23. Kiryushko D, Berezin V, Bock $E$. Regulators of neurite outgrowth: role of cell adhesion molecules. Ann N Y Acad Sci 2004; 1014: 140-154.

24. Shi Y, Mantuano E, Inoue G, Campana WM, Gonias SL. Ligand binding to LRP1 transactivates Trk receptors by a Src family kinase-dependent pathway. Sci Signal 2009; 2: ra18.

25. Qiu Z, Hyman BT, Rebeck GW. Apolipoprotein E receptors mediate neurite outgrowth through activation of $p 44 / 42$ mitogen-activated protein kinase in primary neurons. $J$ Biol Chem 2004; 279: 34948-34956.

26. Ronn LC, Dissing S, Holm A, Berezin V, Bock E. Increased intracellular calcium is required for neurite outgrowth induced by a synthetic peptide ligand of NCAM. FEBS Lett 2002; 518: $60-66$.

27. Horikawa K, Yamada Y, Matsuda T, Kobayashi K, Hashimoto M, Matsu-ura T et al. Spontaneous network activity visualized by ultrasensitive $\mathrm{Ca}(2+)$ indicators, yellow Cameleon-Nano. Nat Methods 2010; 7: 729-732.

28. Salter MW, Kalia LV. Src kinases: a hub for NMDA receptor regulation. Nat Rev Neurosci 2004; 5: 317-328.

29. Almeida RD, Manadas BJ, Melo CV, Gomes JR, Mendes CS, Graos MM et al. Neuroprotection by BDNF against glutamate-induced apoptotic cell death is mediated by ERK and PI3-kinase pathways. Cell Death Differ 2005; 12: 1329-1343.

30. Dwyer TA, Earl DE, Wang $L$. The utility of a new in vitro model of the stroke penumbra. J Neurosci 2008; 28: 6537-6538.

31. Li X, Masliah E, Reixach N, Buxbaum JN. Neuronal production of transthyretin in human and murine Alzheimer's disease: is it protective? J Neurosci 2011; 31: 12483-12490.

32. Wilson BE, Mochon E, Boxer LM. Induction of bcl-2 expression by phosphorylated CREB proteins during B-cell activation and rescue from apoptosis. Mol Cell Biol 1996; 16: $5546-5556$.

33. van der Heide LP, Smidt MP. The BCL2 code to dopaminergic development and Parkinson's disease. Trends Mol Med 2013; 19: 211-216.

34. Fleming CE, Saraiva MJ, Sousa MM. Transthyretin enhances nerve regeneration. J Neurochem 2007; 103: 831-839. 
35. Sousa JC, Marques F, Dias-Ferreira E, Cerqueira JJ, Sousa N, Palha JA. Transthyretin influences spatial reference memory. Neurobiol Learn Mem 2007; 88: 381-385.

36. Buxbaum JN, Roberts AJ, Adame A, Masliah E. Silencing of murine transthyretin and retino binding protein genes has distinct and shared behavioral and neuropathologic effects. Neuroscience 2014; 275: 352-364.

37. Brouillette J, Quirion R. Transthyretin: a key gene involved in the maintenance of memory capacities during aging. Neurobiol Aging 2008; 29: 1721-1732.

38. He C, Qu X, Cui L, Wang J, Kang JX. Improved spatial learning performance of fat-1 mice is associated with enhanced neurogenesis and neuritogenesis by docosahexaenoic acid. Proc Natl Acad Sci USA 2009; 106: 11370-11375.

39. Lazarov O, Robinson J, Tang YP, Hairston IS, Korade-Mirnics Z, Lee VM et al Environmental enrichment reduces Abeta levels and amyloid deposition in transgenic mice. Cell 2005; 120: 701-713.

40. Fitzgerald M, Nairn P, Bartlett CA, Chung RS, West AK, Beazley LD. Metallothionein-IIA promotes neurite growth via the megalin receptor. Exp Brain Res 2007; 183: 171-180.

41. Qiu Z, Strickland DK, Hyman BT, Rebeck GW. alpha 2-Macroglobulin exposure reduces calcium responses to $\mathrm{N}$-methyl-D-aspartate via low density lipoprotein receptor-related protein in cultured hippocampal neurons. J Biol Chem 2002; 277: 14458-14466.

42. Zhang X, Zhang Q, Tu J, Zhu Y, Yang F, Liu B et al. Prosurvival NMDA 2 A receptor signaling mediates postconditioning neuroprotection in the hippocampus. Hippocampus 2015; 25: 286-296.

43. Altar CA, DiStefano PS. Neurotrophin trafficking by anterograde transport. Trends Neurosci 1998; 21: 433-437.

44. Muresanu DF, Buzoianu A, Florian SI, von Wild T. Towards a roadmap in brain protection and recovery. J Cell Mol Med 2012; 16: 2861-2871.

45. Andersen RK, Hammer K, Hager H, Christensen JN, Ludvigsen M, Honore B et al. Melanoma tumors frequently acquire LRP2/megalin expression, which modulates melanoma cell proliferation and survival rates. Pigment Cell Melanoma Res 2015; 28: 267-280.

46. Zang X, Zheng F, Hong HJ, Jiang Y, Song Y, Xia Y. Neutrophil gelatinase-associated lipocalin protects renal tubular epithelial cells in hypoxia-reperfusion by reducing apoptosis. Int Urol Nephrol 2014; 46: 1673-1679.

47. Hibert P, Prunier-Mirebeau D, Beseme O, Chwastyniak M, Tamareille S, Pinet F et al. Modifications in rat plasma proteome after remote ischemic preconditioning (RIPC) stimulus: identification by a SELDI-TOF-MS approach. PLoS One 2014; 9: e85669.

48. Hepponstall M, Ignjatovic V, Binos S, Monagle P, Jones B, Cheung MH et al. Remote ischemic preconditioning (RIPC) modifies plasma proteome in humans. PLoS One 2012; 7: e48284.

49. Suzuyama K, Shiraishi T, Oishi T, Ueda S, Okamoto H, Furuta M et al. Combined proteomic approach with SELDI-TOF-MS and peptide mass fingerprinting identified the rapid increase of monomeric transthyretin in rat cerebrospinal fluid after transient focal cerebral ischemia. Brain Res Mol Brain Res 2004; 129: 44-53.
50. Episkopou V, Maeda S, Nishiguchi S, Shimada K, Gaitanaris GA, Gottesman ME et al. Disruption of the transthyretin gene results in mice with depressed levels of plasma retinol and thyroid hormone. Proc Natl Acad Sci USA 1993; 90: 2375-2379.

51. Willnow TE, Hilpert J, Armstrong SA, Rohlmann A, Hammer RE, Burns DK et al. Defective forebrain development in mice lacking gp330/megalin. Proc Natl Acad Sci USA 1996; 93: 8460-8464.

52. Almeida MR, Damas AM, Lans MC, Brouwer A, Saraiva MJ. Thyroxine binding to transthyretin Met 119. Comparative studies of different heterozygotic carriers and structural analysis. Endocrine 1997; 6: 309-315.

53. Gomes JR, Lobo AC, Melo CV, Inacio AR, Takano J, Iwata $\mathrm{N}$ et al. Cleavage of the vesicular GABA transporter under excitotoxic conditions is followed by accumulation of the truncated transporter in nonsynaptic sites. J Neurosci 2011; 31: 4622-4635.

54. Meijering E, Jacob M, Sarria JC, Steiner P, Hirling H, Unser M. Design and validation of a tool for neurite tracing and analysis in fluorescence microscopy images. Cytometry A 2004; 58 : 167-176.

55. Santos AR, Duarte $C B$. Validation of internal control genes for expression studies: effects of the neurotrophin BDNF on hippocampal neurons. J Neurosci Res 2008; 86: 3684-3692.

56. Pfaffl MW. A new mathematical model for relative quantification in real-time RT-PCR. Nucleic Acids Res 2001; 29: e45.

57. Lambertsen KL, Gregersen R, Drojdahl N, Owens T, Finsen B. A specific and sensitive method for visualization of tumor necrosis factor in the murine central nervous system. Brain Res Brain Res Protoc 2001; 7: 175-191.

58. Ferraz-Nogueira JP, Diez-Guerra FJ, Llopis J. Visualization of phosphatidic acid fluctuations in the plasma membrane of living cells. PLoS One 2014; 9: e102526.

This work is licensed under a Creative Commons Attribution 4.0 International License. The images or other third party material in this article are included in the article's Creative Commons license, unless indicated otherwise in the credit line; if the material is not included under the Creative Commons license, users will need to obtain permission from the license holder to reproduce the material. To view a copy of this license, visit http://creativecommons.org/ licenses/by/4.0/

(C) The Author(s) 2016

Supplementary Information accompanies this paper on Cell Death and Differentiation website (http://www.nature.com/cdd) 